\title{
1 Prediction of perforation into concrete accounting for 2 saturation ratio influence at high confinement
}

\author{
J. Baroth, M. Briffaut, D. Vu, Y. Malecot, L. Daudeville
}

Univ. Grenoble Alpes, CNRS, Grenoble INP, 3SR, F-38000, Grenoble, France

\begin{abstract}
This paper provides both an analytical and a finite element model aiming at better predicting possible perforation of reinforced concrete slabs submitted to impacts. Both models account for free water saturation ratio and high triaxial stress induced into concrete by the impact. Finite element simulations are performed with Abaqus explicit code using a revised constitutive model for concrete; this coupled damage plasticity model (PRM) accounts for strain rate effects and the influence of saturation ratio on the triaxial behavior. Complementary original analytical predictions of ballistic limit and residual velocities are provided for both hard and soft impacts. These predictions depend on a recent deviatoric stress-based formulation of compressive strength of concrete. Numerical and analytical results are consistent with bending and punching experimental tests.
\end{abstract}

Keywords: soft and hard impacts, residual velocity, reinforced concrete, perforation capacity, saturation ratio

* Corresponding author.

E-mail address: jbaroth@univ-grenoble.fr (J. Baroth).

\section{Introduction}

In the past decades, some experimental campaigns have been conducted in order to better understand the response of concrete structures under extreme loads such as explosion or impacts and also to propose new design methods. Some of these experimental campaigns consisted in missile impact tests on reinforced concrete (RC) slabs. Among others, one can quote Meppen tests [1], [2], Vulcain tests [3-5], or the Iris benchmark (Improving Robustness Assessment Methodologies for Structures Impacted by Missiles) [6] and more recently Xu et al works [7]. Some papers published after Iris benchmark provided finite element simulations of all these tests [8-13]. They highlighted different features influencing simulation results such as material models (concrete and steel), strain rate effects, concrete fracture energy or 
1 erosion value. Little available data on concrete material properties is a cause of discrepancies

2 between numerical and experimental results [14]. To have a better the knowledge of the

3 concrete behavior, unconfined compression tests and triaxial compression tests at confining

4 pressures up to $100 \mathrm{MPa}$ have then been conducted on the IRIS high performance concrete

5 (HPC) by Chung et al. [12] and Vu et al. [15].

6 The effect of free water on concrete mechanical behavior has been studied under high or

7 moderate strain rates [16-19]. However, the effect of free water on the mechanical behavior of

8 concrete under high stress level is still an investigate topic, essentially due to a lack of

9 experimental data. In particular, numerical investigations recently investigated the influence

10 of free water content using advanced constitutive models for concrete, in case of thick

11 concrete targets under ogival-nosed projectile impact $[20,21]$. These works emphasize that

12 the water-saturation ratio is shown to be a major parameter that needs to be taken into account

13 for predicting the ballistic performance of concrete targets.

14 The authors of the present study were the first who experimentally highlighted the effect of

15 free water on the maximum deviatoric stress that concrete material can withstand [22,15].

16 They also measured the interstitial pore pressure during a triaxial test and showed that it may

17 reach about the same value as the confining pressure [23]. Consequently, the prediction of the perforation resistance of concrete structures under impacts requires accounting for the influence of free water content on concrete behavior, especially when these structures are massive, their drying process being then very slow.

21 Thus, $\mathrm{Vu}$ et al. [15] conducted triaxial compression tests on IRIS HPC samples with various 22 saturation ratios. $\mathrm{Vu}$ et al. also carried out tests under very high confining pressure (600 MPa) 23 in order to highlight the important effect of the saturation ratio at high mean stress. Only the 24 PRM FE model [24] based on the effective stress concept [25] was proposed to model wet 
1 [12] [15], the coupled damage plasticity model PRM proposed by Pontiroli et al. [24] had

2 been slightly revised [15]. This last version accounts for strain rate, Lode angle and tensile

3 damage [26].

5 In the present paper, the revised PRM model is used to simulate Iris impact tests; numerical 6 and experimental results are compared. Following this study and using recent works [5], [27], analytical predictions for the ballistic limit and residual velocities are derived. Section 2 recalls briefly the analytical formulation proposed by Baroth et al. [5] and the revised PRM constitutive model for concrete. Section 3 presents Iris tests (hard and soft impacts) and in section 4 failure patterns and penetration resistance of concrete slabs are predicted thanks to a transient dynamic finite element analysis. The revised PRM model allows better predicting experimental results than the original model. Finally, section 5 provides and compares experimental results to analytical predictions of ballistic limits and residual velocities for various saturation ratios. It also gives complementary numerical results for soft impacts. Main notations of the paper are gathered in Table 1.

Table 1

18 Main physical quantities and parameters used.

19

\begin{tabular}{|c|c|c|c|c|c|}
\hline Symbol & Parameter & Unit & Symbol & Parameter & Unit \\
\hline$M_{p}$ & Projectile mass & $\mathrm{kg}$ & $f_{c k}$ & $\begin{array}{l}\text { Compressive strength of } \\
\text { concrete ( } 28 \text { days, uniaxial) }\end{array}$ & $\mathrm{Pa}$ \\
\hline$M_{C}$ & Concrete mass (ejection cone) & $\mathrm{kg}$ & $\sigma_{T}$ & Compressive strength (target) & $\mathrm{Pa}$ \\
\hline$u$ & Crushed length & $\mathrm{m}$ & $\begin{array}{l}\sigma_{x}, \sigma_{m} \\
q\end{array}$ & $\begin{array}{l}\text { Principal and mean stresses } \\
\text { Deviatoric stress }\end{array}$ & $\begin{array}{l}\mathrm{Pa} \\
\mathrm{Pa}\end{array}$ \\
\hline$u^{*}$ & $\begin{array}{l}\text { Characteristic crushed } \\
\text { length }\end{array}$ & $\mathrm{m}$ & $q_{\max }$ & Maximum deviatoric stress & $\mathrm{Pa}$ \\
\hline$F_{P}$ & Projectile crushing force & $\mathrm{N}$ & $q_{1}$ & $\begin{array}{l}\text { Critical shear stress of dry } \\
\text { concrete }\end{array}$ & $\mathrm{Pa}$ \\
\hline$A_{P}$ & $\begin{array}{l}\text { Crushed projectile cross- } \\
\text { section }\end{array}$ & $\mathrm{m}^{2}$ & $\sigma_{c_{p 0}}$ & $\begin{array}{l}\text { Ultimate consolidation } \\
\text { stress }\end{array}$ & $\mathrm{Pa}$ \\
\hline$e_{P}$ & Projectile thickness & $\mathrm{m}$ & $\sigma_{t o t}$ & Total stress & $\mathrm{Pa}$ \\
\hline$r_{P 1}$ & Projectile mean radius & $\mathrm{m}$ & $b$ & Biot coefficient & - \\
\hline$V_{0}, V_{C}$ & $\begin{array}{l}\text { Projectile velocity before } \\
\text { impact, ballistic limit }\end{array}$ & $\mathrm{m} / \mathrm{s}$ & $p$ & Pore pressure & $\mathrm{Pa}$ \\
\hline$V_{\text {res }}$ & Residual velocity & $\mathrm{m} / \mathrm{s}$ & $\varepsilon_{\mathrm{v}}$ & Volumetric strain & - \\
\hline$V_{C}^{S}$ & Ballist limit for soft impact & $\mathrm{m} / \mathrm{s}$ & $\lambda$ & Entrained air coefficient & $\mathrm{Pa}$ \\
\hline$u_{P}, u_{T}$ & Displacements of the & $\mathrm{m}$ & $\kappa$ & Capillary porosity & $\mathrm{Pa}$ \\
\hline
\end{tabular}


projectile and target

$\rho_{p} \quad$ Projectile mass density

$d \quad$ Projectile diameter

L Projectile length

$\checkmark \quad$ Poisson's ratio of steel

E Young's modulus of steel

$f_{y} \quad$ Yield strength

$\begin{array}{ll}\mathrm{kg} / \mathrm{m}^{3} & S r \\ \mathrm{~m} & M \\ \mathrm{~m} & \\ - & \rho_{C} \\ \mathrm{~Pa} & e_{T} \\ \mathrm{~Pa} & e\end{array}$

coefficient

saturation ratio

Reinforcement density

Concrete mass density

Target thickness

Perforation limit
$\%$

$\mathrm{kg} / \mathrm{m}^{3}$

$\mathrm{kg} / \mathrm{m}^{3}$

$\mathrm{m}$

$\mathrm{m}$

\section{Perforation capacity of concrete slabs under soft impacts}

This section summarizes the analytical formulation to predict perforation of RC slabs [5] and the main features of the revised PRM constitutive model [15].

\subsection{Analytical perforation prediction in case of soft impacts}

In case of hard impact, various empirical formulae were proposed to predict the ballistic limit or the penetration depth into concrete and RC targets. Among them, Berriaud et al. [26] proposed a perforation limit formula, whose range of validity has been extended later [29], taking into account the missile nose shape influence. The effects of the projectile nose shape on the extent of local damage were also investigated experimentally in case of soft impact [30]. In such case, recent experimental and numerical studies improve the understanding of failure mechanisms in reinforced concrete targets, e.g. [31, 32]. But to the best of authors' knowledge, no analytical formula was proposed except for the prediction of the ballistic limit by Baroth et al. [5]. This formula is based on the distinction between hard and soft impacts proposed by Koechlin \& Potapov [33]; the formula allows determining the crushed length $u$ of the deformable missile:

$u=\operatorname{Max}\left(0, \frac{M_{P}}{2 F_{P}}\left(\left(V_{0}\right)^{2}-\frac{\sigma_{T}-F_{P} / A_{p}}{\rho_{p}}\right)\right) \ldots$

where $M_{p}, V_{0}$ are the projectile mass $(\mathrm{kg})$ and the initial projectile velocity $(\mathrm{m} / \mathrm{s})$ respectively, $\sigma_{T}$ is the compressive strength of the target $(\mathrm{MPa}), \rho_{p}$ the mass density $\left(\mathrm{kg} / \mathrm{m}^{3}\right), F_{P}, A_{P}$ are the crushing force $(\mathrm{N})$ and the crushed projectile cross-section $\left(\mathrm{m}^{2}\right)$ respectively. 
1 If the possible crushed length $u$ of the missile is greater than the characteristic crushed length

$2(u>u *)$, the dissipated energy during crushing is too high, compared to projectile initial

3 kinetic energy to allow perforation. Or else, if the possible crushed length is not long enough

$4 \quad(u<u *)$, the dissipated energy during crushing is not high enough to stop the projectile; there

5 is perforation.

6 Berriaud's model [26] or derived ones are based upon the uniaxial compressive strength after 728 days. Baroth et al. [4] and Zingg et al. [34] have shown that latter parameter is a poor 8 indicator of concrete compressive strength under high confinement. For that reason, the 9 present paper proposes for hard impact an approach based upon the deviatoric strength of 10 concrete that depends on its composition and its saturation ratio [27].

\subsection{Revised PRM constitutive model}

13

The PRM coupled model has been developed in order to deal with computational problems of structures subjected to impact or blast loading [34]. It is based on a coupling between a damage model and the KST plasticity model initially developed for soils [35] and modified in [36]. It includes the calculation of the effective stress defined for a wet concrete to take into account the influence of free water content on the response of concrete [25]. The damage model is based on two damage variables, in compression and tension respectively, in order to simulate the unilateral feature of concrete behavior. In the revised model used in this paper [15], a poro-mechanical approach is used to take into account the effect of free water. The studied porous medium is assumed to be composed of a solid phase (skeleton) and a fluid phase occupying the voids [37]. The classical concept of effective stress is introduced to distinguish the stress in the solid phase with the pore water pressure.

$$
\sigma_{t o t}=\sigma_{M}+b p \text {...(2.2) }
$$

with $\sigma_{t o t}$ the total stress, $\sigma_{M}$ the stress transmitted through the matrix at macroscopic scale, 
$1 \quad p$ the pore water pressure, and $b$ the Biot coefficient which depends on the nature of the

2 porosity. As the material reaches the consolidation point (closure of all the pores not filled

3 with water), the volumetric behavior remains nonlinear because voids filled with water

4 continue to be compacted due to the water compressibility (see [15]). But even if the

5 consequences of the improvements have been shown at the material scale, the assessment of

6 their effects on the numerical prediction of the global response of a concrete slab submitted to

7 impact loading was not carried out.

\section{Presentation of Iris tests}

10

Impact tests were carried out by the Finnish VTT laboratory. Two types of cylindrical projectiles (length $L$ and diameter $d$ ) were launched on rectangular RC slabs of thickness $e_{T}$ mass density $\rho_{T}$. Projectiles and slabs have been designed to simulate hard and soft projectile impacts.

15

\subsection{Projectiles}

The first type of projectile, for hard impact, is filled with concrete and the second type, for soft impact, is hollow. Their characteristics are gathered in Table 2. Projectiles considered for soft impacts are metallic cylinders, whose lowest thickness is $3 \mathrm{~mm}$ over a length of $1 \mathrm{~m}$. Two tests were conducted with initial velocities equal to 110 and $112 \mathrm{~m} / \mathrm{s}$ [14]. The crushing force for this part is around $540 \mathrm{kN}$. Taking into account the effect of strain rate, this force is found around $630 \mathrm{kN}[14]$.

Projectiles used for hard impacts are filled with light concrete cast one month before the test. Their outer diameter is $168 \mathrm{~mm}$. Three tests, denoted a, b, c, were conducted with initial velocities around $135 \mathrm{~m} / \mathrm{s}$. The rear part of the projectile consists of an aluminum bar that allows measuring the residual velocity of the perforating projectile by a system of cameras installed behind the slab. 
Table 2

Projectiles description: cylinders filled with concrete and hollow cylinders [6,14]

\begin{tabular}{llll}
\hline Symbols & Parameters & $\begin{array}{l}\text { Punching test } \\
\text { (hard impact) }\end{array}$ & $\begin{array}{l}\text { Bending test } \\
\text { (soft impact) }\end{array}$ \\
\hline$L, d$ & Missile size $(\mathrm{m})$ & $0.64(\mathrm{~L}) \times 0.1683(\mathrm{~d})$ & $2.11(\mathrm{~L}) \times 0.254(\mathrm{~d})$ \\
$e_{P}, l_{P}$ & Thickness (over the length) & - & $3 \mathrm{~mm}(1 \mathrm{~m})$ \\
& Concrete inside & yes & no \\
$M_{p}$ & Missile mass $(\mathrm{kg})$ & 47.38 & 49.99 \\
$f_{y,}, v$ & Characteristics of steel: Yield limit, & \multicolumn{2}{c}{ 235 MPa, 200 GPa, 0.3 (steel EN1.4432) } \\
& Young's modulus, Poisson's ratio & & \\
$V_{0}$ & Initial velocity $(\mathrm{m} / \mathrm{s})$ & $135.85 ; 134.86 ; 136.46$ & $110.15 ; 111.56$ \\
& (Tests $a ; b ; c)$ & & \\
\hline
\end{tabular}

\subsection{Reinforced concrete slabs}

5 Square RC slabs with $2.1 \mathrm{~m}$ side length are used. Thicknesses of slabs are 15 and $25 \mathrm{~cm}$ for

6 soft and hard impacts respectively. Displacement sensors are located on the front face of the

7 slab to measure displacements at various points (see Fig. 1). Each test was carried out at least

8 twice to assess the test reproducibility that was verified in terms of fracture patterns, slab

9 displacements, rebar deformations, projectile residual velocities. The slabs for hard impacts

10 (25 cm thick) are reinforced by two A500HW steel reinforcement layers with a $10 \mathrm{~mm}$

11 diameter (Fig. 2). The distance between 2 rebars is $90 \mathrm{~mm}$, their length is $1.025 \mathrm{~m}$ and the

12 concrete cover thickness is $30 \mathrm{~mm}$. These slabs have no transverse reinforcement to facilitate

13 the projectile perforation.
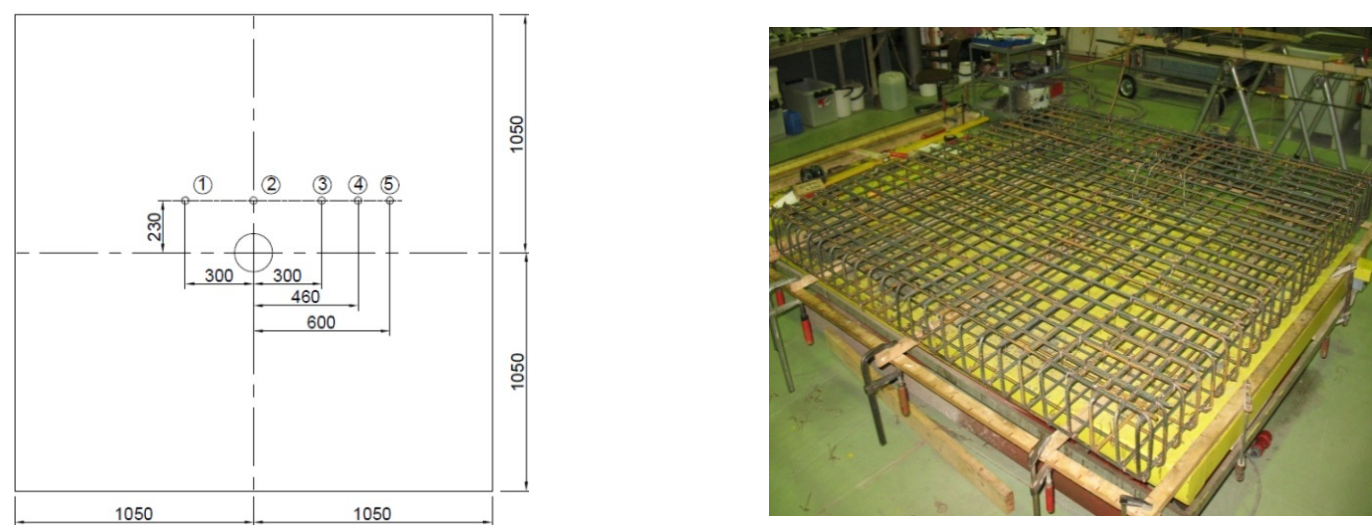
Fig. 1. Positions of displacement sensors on the target front face (perforation test).
Fig. 2. Concrete slab reinforcement.

\subsection{Concrete properties}

2

Table 3

Concrete composition and properties.

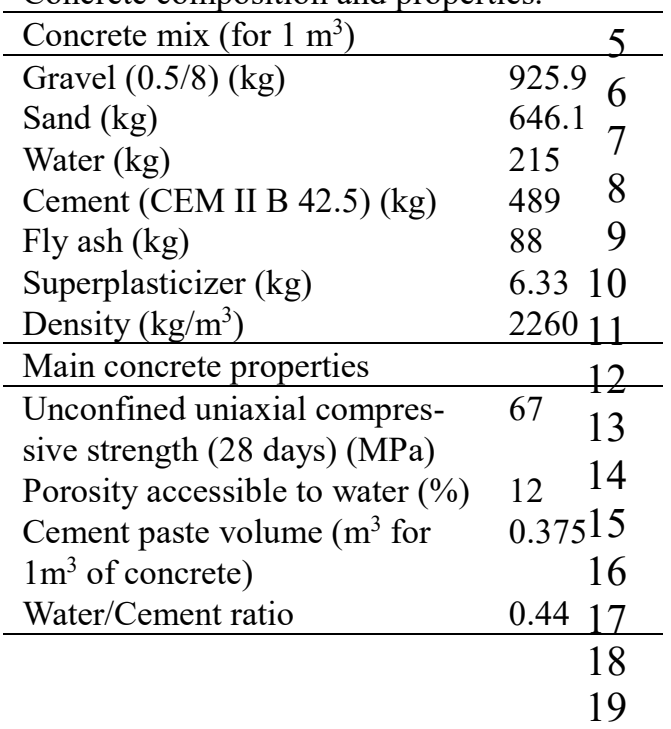

The Iris concrete is representative of that selected for a nuclear reactor building (67 $\mathrm{MPa}$ unconfined compressive strength and 4.5 MPa tensile strength, see composition in Table 3).

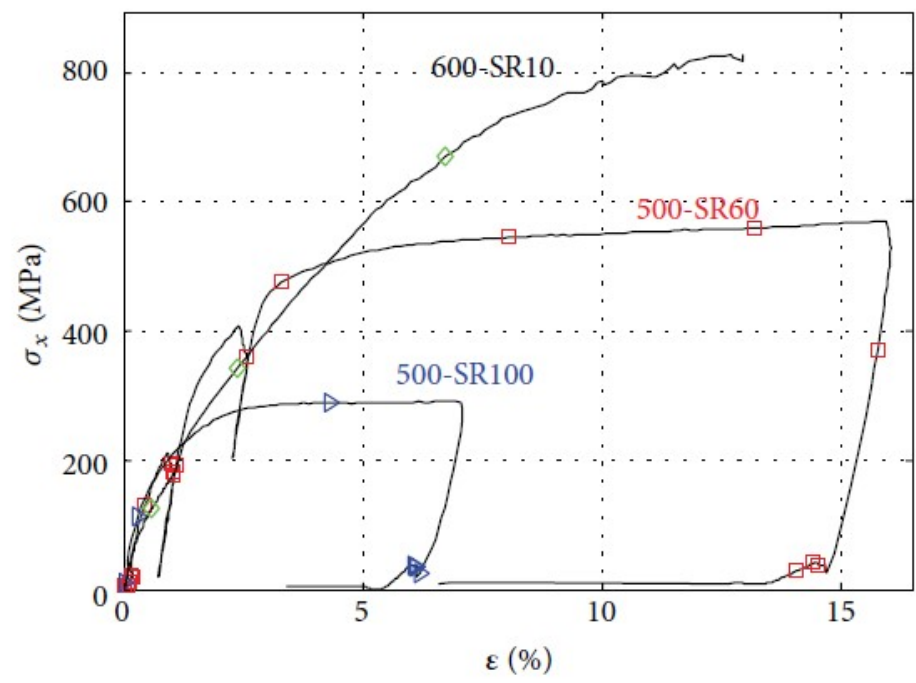

Fig. 3. Axial behavior, comparison of stress-strain curves under triaxial compression at high confinement for various saturation ratios (circles: $S r=10 \%$; squares: $S r=60 \%$; triangles: $S r=100 \%$ ) [15].

Triaxial compression tests were performed on Iris fully saturated concrete samples with triaxial confining pressures up to $100 \mathrm{MPa}$ [6]. In addition, $\mathrm{Vu}$ et al. [15] performed tests at very high confining pressure and various saturation conditions (500 $\mathrm{MPa}-60 \%$; $600 \mathrm{MPa}-$ 10\%). Figure 3 displays test results given by $\mathrm{Vu}$ et al. [15]; it shows the stress-strain curve of 3 samples with various saturation ratios $S r=10,60$ and $100 \%$ under triaxial compression at high confinement (500 and $600 \mathrm{MPa}$ ). Under high confinement, the compressive strengths reach values varying between 250 and more than $800 \mathrm{MPa}$ for $\mathrm{Sr}=100$ and $10 \%$ respectively. $\mathrm{Vu}$ et al. $[15,22]$ explain that the strength loss of wet concrete is due to the interstitial water pressure effect. Under moderate confinement, the material is not compacted enough to close the voids and to provoke an interstitial water pressure effect. Consequently, no influence of 
1 free water on the concrete behavior is observed, as modelled by [38]. The influence of free

2 water appears only under dynamic loading with significant strain-rate effect $[39,40]$.

3

6

\section{Finite element modeling of the perforation test}

\subsection{Finite element discretization}

Given the double symmetry of the system, only a quarter of the slab is modelled. The projectile shown in Fig. 4 is a $168 \mathrm{~mm}$ diameter steel tube filled with lightweight concrete. Its length is $64 \mathrm{~cm}$. Since the thin hollow metallic cylinder has no influence, 3D finite elements (C3D8R) are used to mesh the projectile; the weight of one quarter of the projectile is $11.75 \mathrm{~kg}$.

Fig. 4. Mesh of a quarter of projectile and slab [15].

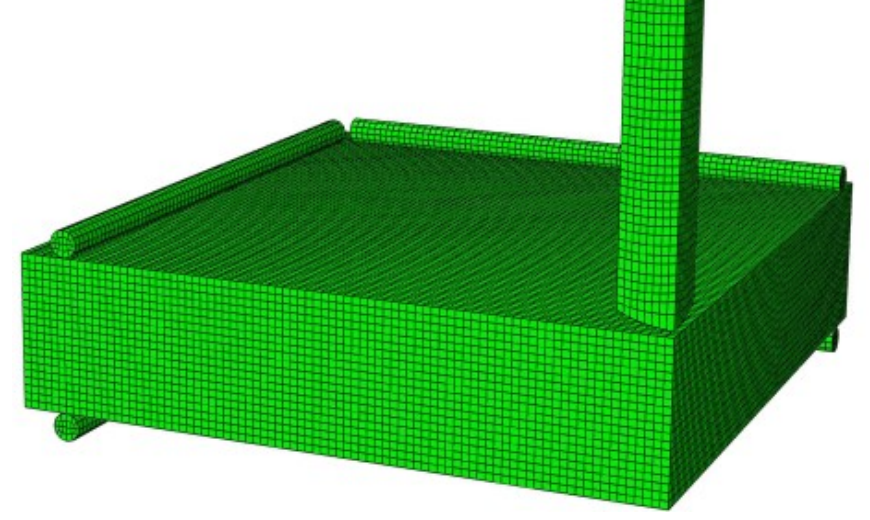

The concrete finite element mesh is homogeneous with a $12.5 \mathrm{~mm}$ element size. This mesh refinement has been chosen, knowing that PRM model uses Hillerborg et al. regularization technique [41] and that the non-mesh dependency of PRM model has been shown in [42]. We also remind that this macroscopic constitutive behavior for concrete accounts for strain-rate in tension. In compression, strain-rate effect due to inertia is accounted in the 3D FE modeling. The concrete plate consists finally of 129,488 C3D8R finite elements. The rebars are modeled using 2-node beam elements with a circular cross-section (see Table 4). The $10 \mathrm{~mm}$ rebars 
1 are meshed with 3608 beam elements. The reinforced concrete slab is surrounded by a U

2 shape metal frame that is modelled using 11632 C3D8R elements of the same size as the

3 concrete elements. The thickness of this frame is $25 \mathrm{~mm}$. It is supported by steel cylinders that

4 block the displacement but allow a possible rotation.

5 Table 4

6 Characteristics of rebars and of half slabs.

\begin{tabular}{|c|c|c|c|}
\hline Geometry of slab / Type of test & Punching & Bending & Unit \\
\hline Slab dimensions (two directions) & \multicolumn{2}{|c|}{1.05} & $m$ \\
\hline Thickness of the slab $\left(e_{T}\right)$ & 25 & 15 & $\mathrm{~cm}$ \\
\hline Reinforcement density $\left(M_{a}\right)$ & 54.6 & 105 & $\mathrm{~kg} / \mathrm{m}^{3}$ \\
\hline Rebar diameter & \multicolumn{2}{|c|}{10} & $m m$ \\
\hline Rebar number (two directions) & \multicolumn{2}{|c|}{12} & \\
\hline Concrete coating & \multicolumn{2}{|c|}{20} & $m m$ \\
\hline
\end{tabular}

\subsection{Simulation results}

10

11 In this section, simulation results obtained either with the original coupled PRM model or

12 with the revised coupled PRM model are compared. Figure 5 shows the projectile and the 13 deformed slab at time $30 \mathrm{~ms}$ (end of the impact test, Fig. 5a). Figure 5b also displays the 14 numerical evolution of the projectile velocity for both models (i.e. before and after 15 improvement) during a perforation test into a fully saturated $\mathrm{RC}$ slab. Both calculations are 16 blind simulations. From this figure one can conclude that the perforation prediction is 17 significantly improved with the revised PRM model; the predicted residual velocity is close to 18 the experimental one.
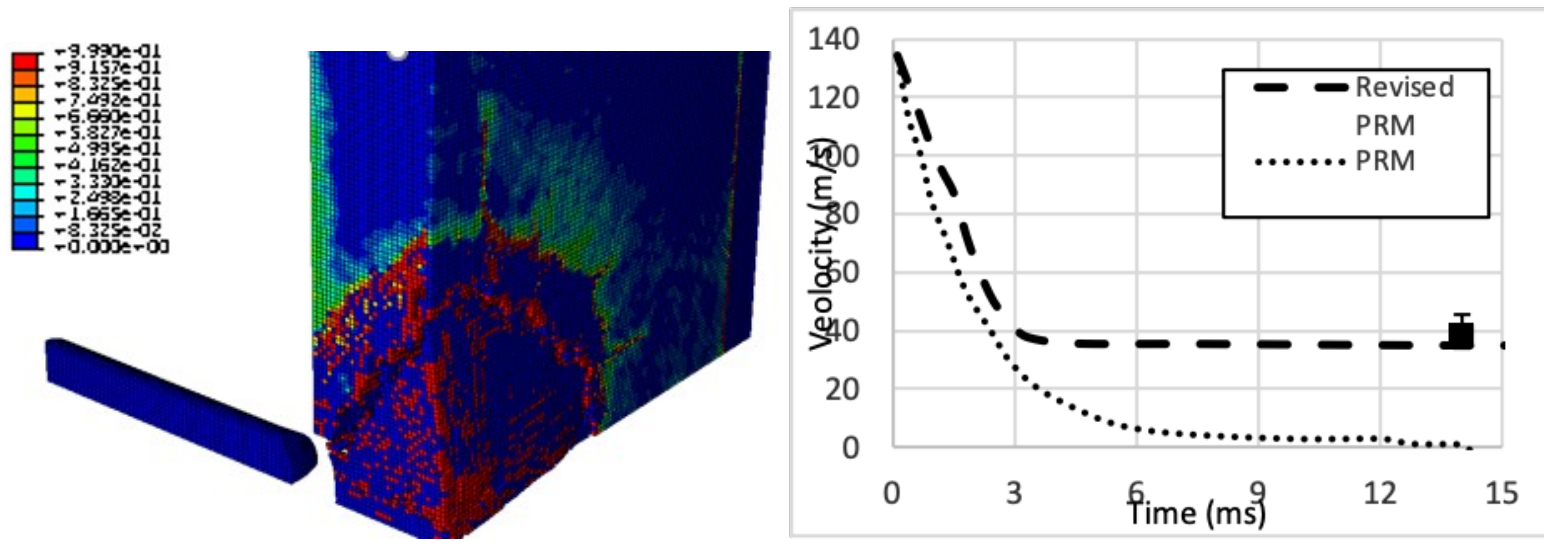
2 Fig. 5. Numerical results using revised PRM, accounting for free water: projectile and the deformed slab at time $30 \mathrm{~ms}$ corresponding to the end of the impact test (a), experimental and numerical evolutions of the projectile velocity (b)

Table 5 provides numerical predictions of residual velocities at low saturation ratios, which

9 prediction described in the next paragraph.

10 Table 5

11 Experimental and numerical residual velocities for different saturation ratios.

\begin{tabular}{cccccc}
\hline & Exp & $\begin{array}{c}S r \approx 99 \% \\
(\text { num })\end{array}$ & $\begin{array}{c}S r \approx 80 \% \\
(\text { num })\end{array}$ & $\begin{array}{c}S r \approx 40 \% \\
(\text { num })\end{array}$ & $\begin{array}{c}S r \approx 0 \% \\
(\text { num })\end{array}$ \\
\hline Residual velocity $(\mathbf{m} / \mathbf{s})$ & 33.8 & 35.18 & 16.73 & 12.21 & 11 \\
\hline
\end{tabular}

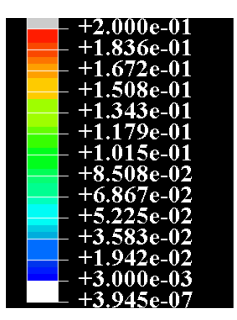

$\stackrel{1}{a} x$

a)
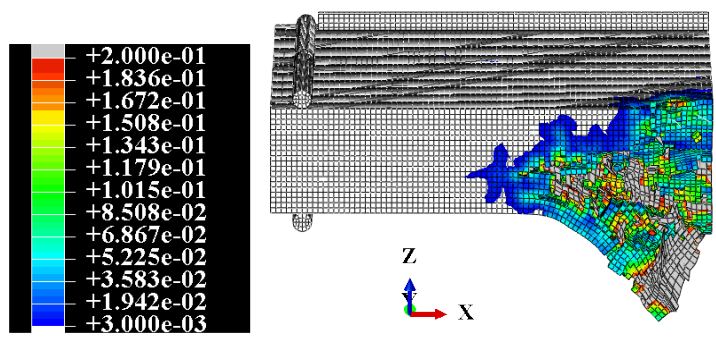

b)

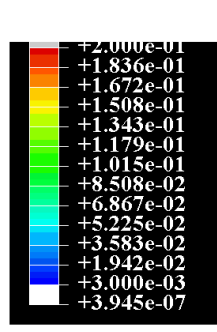

$\mathrm{x} \leftrightarrow$

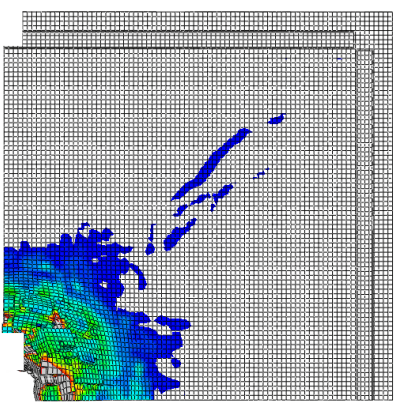

c)

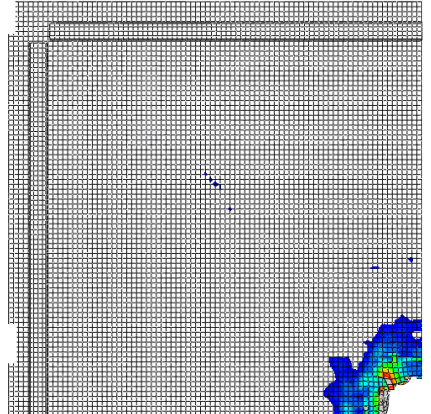

$\stackrel{4}{4}$

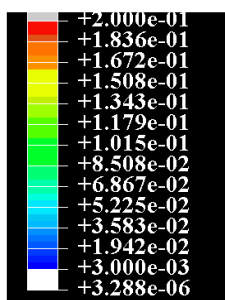

$\stackrel{x}{a}$

a)
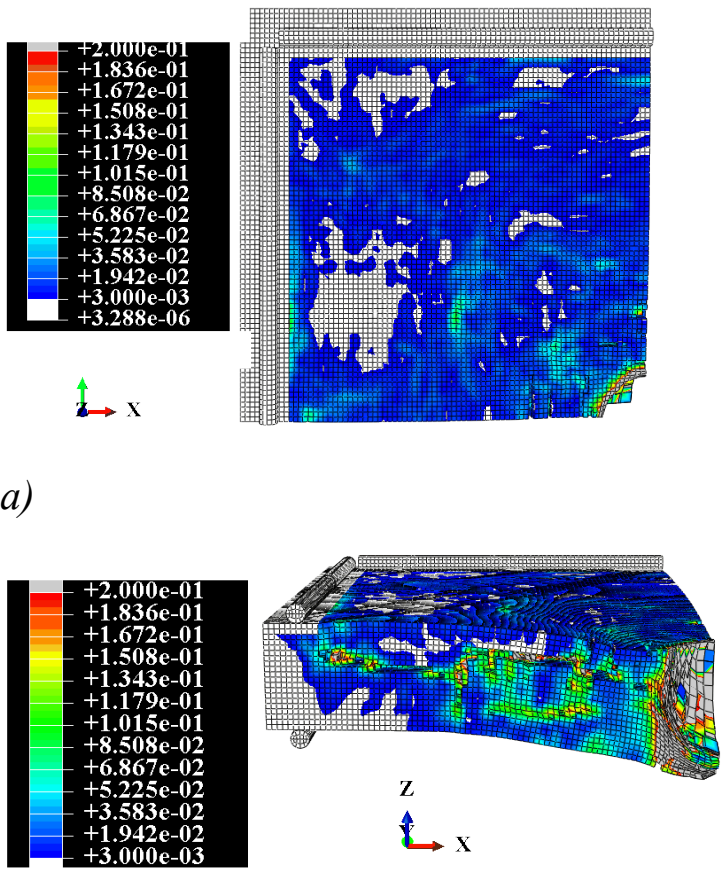

$\llcorner\mathrm{x}$ b)
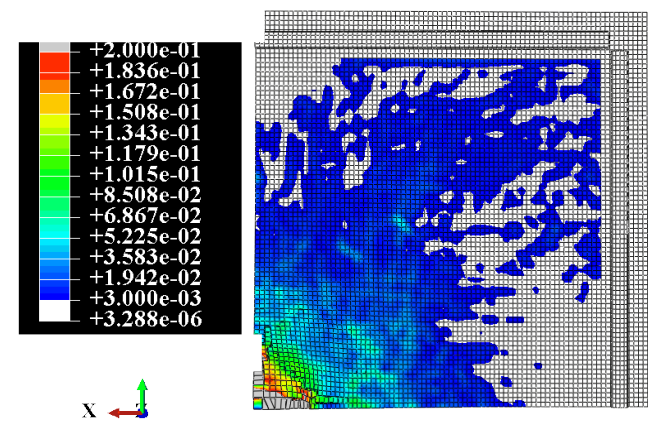

c) 
Fig. 6. Maximal principal strain with the revised PRM model at the end of the perforation simulation: Front face (a), cross section (b), rear face (c).

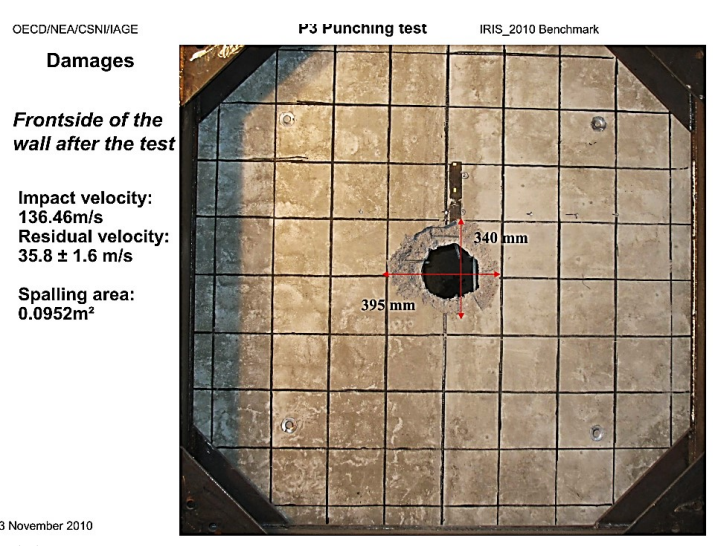

(a)
Fig. 7. Maximal principal strain with the original PRM at the end of the perforation simulation: Front face (a), cross section (b), rear face $(\mathrm{c})$.

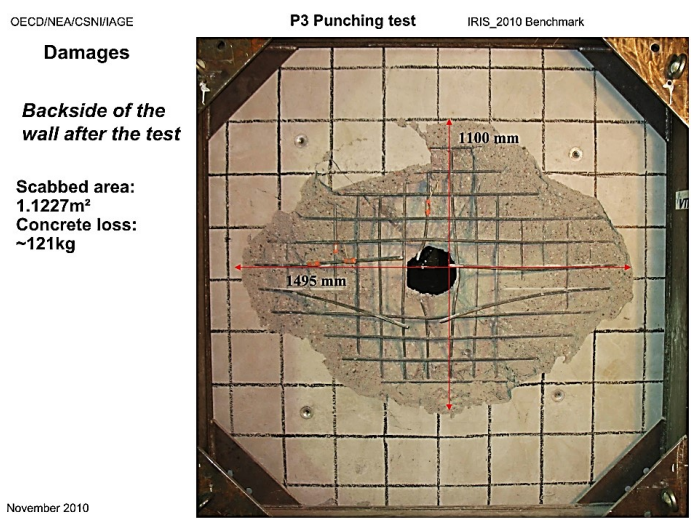

(b)

Fig. 8. Experimental observed failure patterns of punching test (IRIS Benchmark [6]): font face (a), rear face (b).

2 The effect of the model revision on the fracture pattern can be observed on Fig. 6 and Fig. 7.

3 The original PRM leads to a larger plasticity zone (See Fig. 7), whereas the revised PRM model allows activating the damage in the impact zone more extensively (Fig. 6). This failure pattern is closer from the experimental one that can be seen on Fig. $\mathbf{8}$ and leads to a higher residual velocity (Fig. 5).

\section{Analytical prediction of the perforation (soft and hard impacts)}

In this section, analytical predictions of ballistic and residual velocities are discussed. The

11 analytical estimation depends on the ultimate compressive strength of the target $\sigma_{T}$, which

itself depends on the saturation ratio, as illustrated in Fig. 3. In the following, the strength of concrete is estimated according to Malecot et al. [27], who propose to consider the maximum deviatoric stress.

\subsection{Prediction of the maximum deviatoric stress for Iris concrete}

Malecot et al. [27] defined an empirical evolution of the maximum deviatoric stress $q_{\max }$ in concrete depending on its composition and its porosity (See Appendix). This formula has been developed from several concrete compositions with some of them are close to those of 
1 Iris concrete. Table 6 displays predictions of the maximum deviatoric stress $q_{\max }$ versus the

2 saturation ratio $\mathrm{Sr}$ according to this formula for Iris concrete.

3

4

5

6

7

9

10

11

12

rigid. Berriaud's formula [22] can then be used to predict the ballistic limit.

$V_{c}^{2}=1.89 f_{c k}\left(\frac{f_{c k}}{\sigma_{0}}\right)^{-1 / 2} \rho_{T}^{1 / 3}\left(\frac{d e_{T}^{2}}{M_{P}}\right)^{4 / 3} N^{2}\left(0.35\left(\frac{M_{a}}{M_{a 0}}\right)^{0.7}+0.65\right)^{2}$

Table 6

Maximum deviatoric stress $q_{\max }\left(S_{r}\right)$ (MPa), for different saturation ratios for two concretes using empirical formula defined in [27]

\begin{tabular}{cccccc}
\hline & $f_{c k}(\mathrm{MPa})$ & $S r \approx 99 \%$ & $S r \approx 80 \%$ & $S r \approx 40 \%$ & $S r \approx 0 \%$ \\
\hline Iris [15] & 67 & 300 & 406 & 738 & 1217 \\
\hline$[24]$ & 28.7 & 214 & 329 & 692 & 1217 \\
\hline
\end{tabular}

\subsection{Ballistic and residual velocities in case of hard impacts (punching tests)}

For these tests, the cylindrical part of projectiles is filled by concrete and thus considered as

where $f_{c \mathrm{c}}$ is the uniaxial compressive strength of concrete after 28 days $(\mathrm{MPa}), M_{a}$ the

reinforcement density $\left(\mathrm{kg} / \mathrm{m}^{3}\right), M_{P}$ the projectile mass $(\mathrm{kg}), e_{T}$ the thickness of the target $(\mathrm{m})$,

$N$ the nose shape factor and $M_{a 0}, \sigma_{0}$ constants.

Nevertheless, the latter formula is based on the uniaxial compressive strength of the target

that is a poor indicator of concrete impact strength. This parameter does not account for the

effect of water saturation or high confinement conditions [24]. In Eq (5.1) $f_{c k}$ is thus replaced

21 by $q_{\max }\left(S_{r}\right)$ and the factor $1.89 f_{c k}\left(\frac{f_{c k}}{\sigma_{0}}\right)^{-1 / 2}$ in Eq (5.1) is replaced by $a\left(q_{\max }-q^{*}\right)^{1 / 2}$ with $a$ and $q^{*}$

to be identified from [24] and Iris tests results (see Table 6).

23

$$
V_{c}^{2}=a \sqrt{q_{\max }-q^{*}} \rho_{T}^{1 / 3}\left(\frac{d e_{T}^{2}}{M_{P}}\right)^{4 / 3} N^{2}\left(0.35\left(\frac{M_{a}}{M_{a 0}}\right)^{0.7}+0.65\right)_{25}^{2}
$$

26 The resulting analytical residual velocity is then obtained considering the kinetic energy

27 balance, accounting for mass loss, whose influence can be significant [31]: 
$1 \quad V_{\text {res }}=\sqrt{\frac{M_{P}\left(V_{0}^{2}-V_{C}^{2}\right)}{M_{P}+M_{c}}} \ldots$

2 where $M_{c}$ is the ejected concrete mass, estimated from the formula given in [43], which gives

3 a reasonable order of magnitude:

$4 \quad M_{c}=\frac{\pi}{3}\left(r^{2}+r_{c}^{2}+r . r_{c}\right) x \rho_{T} \ldots$

5 where $\rho_{T}$ is the mass weight of the concrete, $r$ is the radius of the hole created in the slab, $r_{c}=$

$6 \quad\left(d+3,5 e_{T}\right) / 2$, and $x$ equal or less than $e_{T}$.

7 The estimation of the residual velocity is concluded applying Eqs. (5.2)-(5.4), with values of

8 parameters that can be found in Tables $2, \mathbf{3}, \mathbf{4}$ and $\mathbf{7}$, for saturated concrete $(\mathrm{Sr}=100 \%)$.

9 Table 7

10 Parameters used to apply Eqs. 5.2-5.4 to estimate the residual density (Eq. 5.3) for $S r=100 \%$

11

\begin{tabular}{cccc}
\hline Symbol & Parameter & Value & Unit \\
\hline$N$ & Nose shape factor & 1.18 & - \\
$\sigma_{0}$ & Reference compressive strength & 36.6 & $\mathrm{MPa}$ \\
$M_{a 0}$ & Reference reinforcement density & 200 & $\mathrm{~kg} / \mathrm{m}^{3}$ \\
$M_{a}$ & Reinforcement density & & \\
$a$ & Fitting parameter & 7389 & - \\
$q^{*}$ & Fitting deviatoric stress & 139.2 & $\mathrm{MPa}$ \\
\hline
\end{tabular}

This formula allows comparing this analytical residual velocity with experimental and FE estimations (see Table 5) for a saturation ratio close to $100 \%$. One can see in Fig. 9 that this analytical residual velocity appears in the average of experimental velocities.

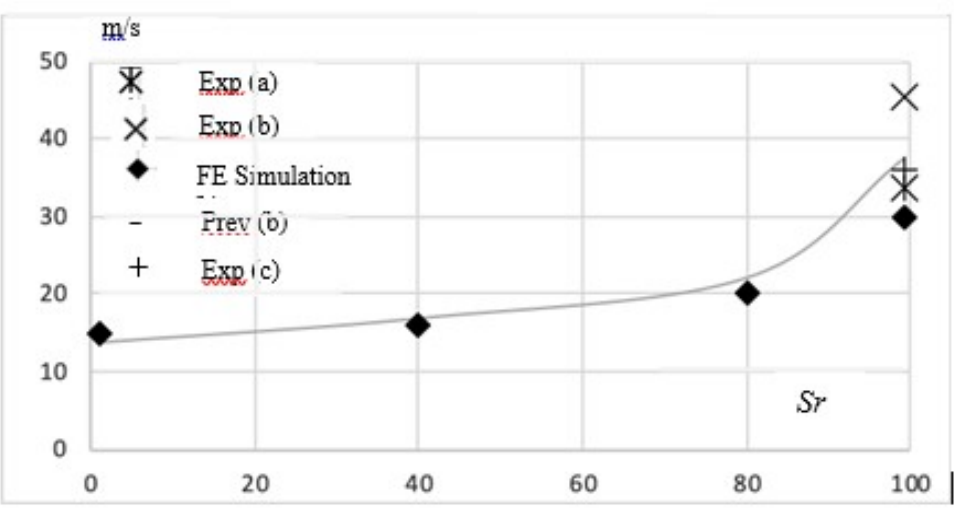

Fig. 9. Experimental, numerical and analytical residual velocities.

19 For non-saturated targets, no experiment has been carried out. Only the FE and analytical 20 predictions can be compared. In this case, to account for the saturation ratio influence, the 21 analytical ballistic velocity is written as:

$$
V_{c}^{2}=a \sqrt{\alpha q_{\max }-q^{*}} \rho_{c}^{1 / 3}\left(\frac{d e_{Y}^{2}}{M_{P}}\right)^{4 / 3} N^{2}\left(0.35\left(\frac{M_{a}}{M_{a 0}}\right)^{0.7}+0.65\right)^{2}
$$


3 with $\alpha=\alpha\left(q_{\max }(S r)\right)$ the saturation ratio influence factor defined such that

$4 \quad \alpha\left(q_{\max }\right)=\left(b q_{\max }^{2}+c q_{\max }+d \sqrt{q_{\max }}+e\right) \ldots$

5 where $(b, d, c, d)$ are fitting parameters respectively found equal to $\left(4.93 .10^{-6},-0.0235,0.821\right.$, $-6.85)$

7

\subsection{Case of soft impacts (bending tests)}

9

10 In case of soft impact, the ballistic limit $V_{C}^{S}$ has been proposed in [5]. It takes into account the

11 crushed length $u$ of the projectile $(\mathrm{m})$, its crushing force $(\mathrm{N})$ of the finest part of the projectile,

12 denoted $F_{P}$, and the hard impact ballistic limit $V_{C}(\mathrm{~m} / \mathrm{s})$, such that

$13 \quad V_{C}^{S}=\sqrt{V_{C}^{2}+\frac{2 F_{p} u}{M_{P}}} \ldots$

14 Perforation occurs when $u \geq u^{*}$, defined as the characteristic crushed length (Eq. 2.1). This length has been defined in [5] depending on the uniaxial compressive strength $f_{c k}$. Accounting

16 for the maximal deviatoric stress $q_{\max }$, this length is define as:

$u=\operatorname{Max}\left(0, \frac{M_{P}}{2 F_{P}}\left(\left(V_{0}\right)^{2}-\frac{q_{\max }-F_{P} / A_{p}}{\rho_{p}}\right)\right) \ldots$

where $M_{p}, V_{0}$ are the projectile mass $(\mathrm{kg})$ and the initial projectile velocity $(\mathrm{m} / \mathrm{s})$ respectively, $\rho_{p}$ the mass density $\left(\mathrm{kg} / \mathrm{m}^{3}\right), F_{P}, A_{P}$ are the crushing force $(\mathrm{N})$ of the finest part of the projectile and the crushed projectile cross-section $\left(\mathrm{m}^{2}\right)$ respectively.

21 Two estimations of the crushing strength, with and without strain-rate effect, are reported in

Table 8, in order to estimate the crushed length. Ballistic limits defined in Eqs. 5.5 and 5.7 
1 are also provided. The estimated crushed length is clearly closer to experimental measures if

2 the strain effect is taken into account.

3 Table 8

4 Comparison between experimental and analytical predicted characteristics for Iris soft impacts

\begin{tabular}{ccccc}
\hline Characteristics & Experiments & \multicolumn{3}{c}{ Predictions } \\
& Soft impact & Soft & impacts & Hard impact \\
\hline Crushing force & unknown & $540 \mathrm{kN}$ & $630 \mathrm{kN}$ with strain & - \\
$(\mathrm{kN})$ & & {$[14]$} & rate effet [14] & \\
Velocities & (initial velocities) & (estimated & ballistic & limits) \\
$(\mathrm{m} / \mathrm{s})$ & $V_{0}=110.1-111.6 \mathrm{~m} / \mathrm{s}$ & $V_{C}^{S}=126.8-$ & $V_{C}^{S}=140.2-$ & $V_{C}=86 \mathrm{~m} / \mathrm{s}$ \\
& & $127.4 \mathrm{~m} / \mathrm{s}$ & $140.8 \mathrm{~m} / \mathrm{s}$ & \\
Crushed length & $96-98 \mathrm{~cm}$ & $80-82 \mathrm{~cm}$ & $97-99 \mathrm{~cm}$ & - \\
\hline
\end{tabular}

5

\section{Conclusion}

This study has proposed numerical and analytical studies of impact tests (punching and bending) on RC slabs, conducted by OECD/NEA IAGE working group (Iris 2010 and 2012 benchmark projects). Both hard and soft impact analyses have been performed. Analytical estimations of ballistic and residual velocities have been proposed. The originality of these estimations is to account for a realistic triaxial compression strength. For hard impact, the residual velocity prediction is based on a kinetic energy balance and an analytical formula inspired by Berriaud's regression formula which gives the ballistic limit. The material strength of concrete used in this analytical formula is not the unconfined compressive strength but the maximum deviatoric strength that depends on the water saturation ratio. In case of soft impact, this strength is also used to predict the ballistic limit and the crushed lengths of the deformable projectiles. Predicted analytical crushed lengths are closer to experimental ones if the strain rate effect is taken into account.

The hard impact test has also been modeled with the finite element code Abaqus explicit using the revised PRM constitutive model for concrete, accounting for strain rate effects and the saturation ratio. The comparison of FE and experimental results clearly show a better prediction of failure patterns. The FE model allows correctly predicting the residual velocity of the projectile for saturated concrete slabs, but also provides estimations of concrete slab 
1 response for different saturation ratio values. Numerical and analytical estimations are consistent thanks to a saturation ratio influence factor accounted in the analytical formula.

\section{Acknowledgments}

This research has been partially performed with the financial support of CEA Gramat and IRSN. Authors also thank the Research Centre of Finland VTT for kindly providing test results to all benchmark participants.

\section{References}

[1] Jonas W., Meschkat R., Riech H., Rüdiger E., « Experimental investigations to determine the kinetic ultimate bearing capacity of reinforced concrete slabs subject to deformable missiles », Proc. 5th SMiRT, Berlin, Germany, 1979, J8/3.

[2] Nachtsheim W., Stangenberg F., «Interpretation of results of Meppen slab tests - Comparison with parametric investigations », Nuclear Engrg and Design, vol. 75, n², 1982, p. 283-290.

[3] Pontiroli C, Rouquand A, Baroth J, Daudeville L. Soft projectile impacts analysis on thin reinforced concrete slabs: Tests, modelling and simulations, European J of Environmental and Civil Eng 2012;16:1058-1073.

[4] Baroth J, Daudeville L, Malecot Y, About empirical models predicting the missile perforation of concrete barriers, European J of Environmental and Civil Eng 2012;16(3):1074-1089.

[5] Baroth J., Malecot Y., Boukria Z., Briffaut M., Daudeville L., Prediction of the perforation of targets impacted by deformable projectiles, International J. of Impact Engrg, 2015:80, 36-44.

[6] NEA. Iris_2010, Improving robustness assessment methodologies for structures impacted by missiles, workshop proceedings, IRSN editor, 2010.

[7] Xu, L., Cai, F., Xue, Y. et al. Numerical Analyses of Local Damage of Concrete Slabs by Normal Impact of Deformable Solid Projectiles. KSCE J Civ Eng 23, 5121-5132 (2019).

[8] Martin O., Centro V., Schwoertzig T., Finite element analysis on the Meppen-II-4 Slab Test, Nuclear Engineering and Design 247 (2012) 1- 10.

[9] Martin O., Centro V., Schwoertzig T., Finite element analysis on the VTT-IRSN flexural failure test, Nuclear Engineering and Design 252 (2012) 88- 95.

[10] Orbovic N., Sagals G., Blahoianu A., Influence of transverse reinforcement on perforation resistance of reinforced concrete slabs under hard missile impact, Nuclear Engineering and Design 295 (2015) 716-729.

[11] Orbovic N., Tarallo F., Rambach J.-M., Sagals G., Blahoianu A., Iris 2012 OECD/NEA/CSNI benchmark: Numerical simulations of structural impact, Nuclear Engineering and Design 295 (2015) 700-715.

[12] Chung C., Leea J., Jung R., Numerical simulations of missile impacts on reinforced concrete plates: Iris2010/2012 benchmark project, Nuclear Engineering and Design 295 (2015) 747-758.

[13] Lee H.-K., Kim S.-E. Structural behavior of SC panel subjected to impact loading using finite element analysis, Nuclear Engineering and Design 295 (2015) 96-105.

[14] Moore J et al. Iris 2010 International Benchmark, Improving robustness assessment methodologies for structures impacted by missiles, workshop proceedings, Working Group of components and structures, report of team ENSI / B\&H, IRSN editor, 2010.

[15] Vu X.D., Briffaut M.,Malecot Y., Daudeville L. and Ciree B., Influence of the Saturation Ratio on Concrete Behavior under Triaxial Compressive Loading, Hindawi Publishing Corporation Science and Technology of Nuclear Installations, vol 2015, Article ID 976387, 10 p.

[16] Rossi P., Van Mier J. G. M., Boulay C., Le Maou F. (1992). The dynamic behaviour of concrete: influence of free water. Materials and Structures, 25(9), 509-514.

[17] Zhou J., Chen X., Wu L., Kan X. (2011). Influence of free water content on the compressive mechanical behaviour of cement mortar under high strain rate. Sadhana, 36(3), 357. 
[18] Wu S., Chen X., Zhou J. (2012). Influence of strain rate and water content on mechanical behavior of dam concrete. Construction and Building Materials, 36, 448-457.

[19] Sun X., Wang H., Cheng X., Sheng, Y. (2020). Effect of pore liquid viscosity on the dynamic compressive properties of concrete. Construction and Building Materials, 231, 117143.

[20] Forquin, P, Sallier L., Pontiroli C. , A numerical study on the influence of free water content on the ballistic performances of plain concrete targets, Mechanics of Materials, Vol. 89, 015, pp 176-189

[21] Zhao FQ, Wen HM., Effect of free water content on the penetration of concrete, International J. of Impact Engrg, Vol 121 , 2018 , pages 180-190

[22] Vu X.H., Malecot Y, Daudeville L, Buzaud E., «Experimental analysis of concrete behavior under high confinement: Effect of the saturation ratio ", International J. of Solids and Structures, vol. 46, n5, 2009, p. $1105-1120$

[23] Accary A., Malecot Y., Daudeville L. 2019. Design and evaluation of a deformable sensor for interstitial pore pressure measurement in concrete under very high stress level. Applied Sciences. 9(13): 2610

[24] Pontiroli C., Rouquand A., Mazars J., « Predicting concrete behaviour from quasi-static loading to hypervelocity impact. An overview of the PRM Model », European J. of Environmental and Civil Engrg, vol 14, $\mathrm{n}^{\circ}$ 6-7, 2010, p.703-727.

[25] Mariotti C., Perlat J.P., Guerin J.M., 2003. A numerical approach for partially saturated geomaterials under shock, Int. J. of Impact Engineering, 28: 717 - 741.

[26] Erzar, B., Pontiroli C., Buzaud E. Ultra-high performance fibre-reinforced concrete under impact: experimental analysis of the mechanical response in extreme conditions and modelling using the Pontiroli, Rouquand and Mazars model. Philosophical Transactions of the Royal Society A: Mathematical, Physical and Engineering Sciences, 2017, vol. 375, no 2085, p. 20160173.

[27] Malecot Y, Zingg, Briffaut M, Baroth J., Influence of free water on concrete triaxial behavior: The effect of porosity, Cement and Concrete Research 120 (2019) 207-216.

[28] Berriaud C, Dulac J, Sokolovsky A, Labrot R, Gueraud R, Avet-Flancard R. Local behaviour of reinforced concrete walls under missile impact, Nucl Eng Des, 1978;45(2):457-469.

[29] Berriaud C., Dulac J., Perrot J., Avet-Flancard R., Impact on concrete: Synthesis of French Studies, Proc. 7th SMiRT, Chicago, USA, 1983, paper n ${ }^{\circ} \mathrm{J} 8 / 2$.

[30] Ohno T., Uchida T., Matsumoto N., Takahashi Y., Local damage of reinforced concrete slabs by impact of deformable projectiles, Nuclear Engineering and Design 138(1) (1992) 45-52.

[31] Guo L., He Y., Zhang X.F., Pang C.X., Qiao L., Guan Z.W., Study mass loss at microscopic scale for a projectile penetration into concrete, International Journal of Impact Engineering 72 (2014) 17-25.

[32] Ardila-Giraldo O.A., Pujol S., Failure mechanisms of small-scale reinforced concrete beams impacted by soft missiles, Structures 20 (2019) 620-634

[33] Koechlin P, Potapov P. Classification of soft and hard impacts - Application to aircraft crash, Nucl Eng Des, 2009;239:613-618.

[34] Zingg L, Briffaut M, Baroth J, Malecot Y (2016) Influence of cement matrix porosity on the triaxial behaviour of concrete. Cem Concr Res 80:52-59.

[35] Krieg R.D., A simple constitutive description for soils and crushable foams, 1972.

[36] Swenson D.V, Taylor L.M., A finite element model for the analysis of tailored pulse stimulation of boreholes, Int. J. Numer. Anal. Methods Geomech. 7 (1983) 469-484

[37] Coussy O., 1995. Mechanics of Porous Continua, Wiley Ltd, New York.

[38] Benniou, H., Accary, A., Malecot, Y. et al. Discrete element modeling of concrete under high stress level: influence of saturation ratio. Comp. Part. Mech. (2020). https://doi.org/10.1007/s40571-020-00318-5

[39] Cadoni E., Labibes K., Albertini C., Berra M. and Giangrasso M., Strain-rate effect on the tensile behaviour of concrete at different relative humidity levels, Materials and Structures, Vol. 34, 2001, pp 21-26.

[40] Erzar B. and Forquin P., Experiments and mesoscopic modelling of dynamic testing of concrete, Vol. 43(9), 2011 , pp. 505-527

[41] Hillerborg A., Modéer M., Petersson P.-E. Analysis of crack formation and crack growth in concrete by means of fracture mechanics and finite elements. Cement and concrete research, 1976, vol. 6, no 6, p. 773-781.

[42] Mazars J., Dufour F., Giry C. Concrete under various loadings, way to model in a same framework: damage, fracture and compaction. Computational Modelling of Concrete Structures, 2010, p. 45-58.

[43] Hugues G., hard missile impact on reinforced concrete, Nucl. Eng Des., 1984 ;77(1) :23-35.

[44] Vu X.H., Y. Malecot Y., Daudeville L., Buzaud E., Effect of the water/cement ratio on concrete behavior under extreme loading, Int. J. Numer. Anal. Methods Geomech.33 (17) (2009) 1867-1888.

\section{Table captions}


1 Table 1: Main physical quantities, their units and the coefficients used.

2 Table 2: Projectiles description: cylinder filled with concrete and hollow cylinder.

3 Table 3: Concrete properties.

4 Table 4: Characteristics of the rebars.

5 Table 5: Experimental and numerical residual velocities for different saturation ratios.

6 Table 6: Analytical maximum deviatoric stress for different saturation ratios

7 Table 7: Parameters used to apply Eqs. (5.2-4) to estimate the residual density (Eq. 5.3) for $S r=100 \%$

8 Table 8: Comparison between experimental and analytical characteristics for Iris soft impacts

9 Table 11.1: Validity ranges for parameters used in Eq. (9.1) (min and max values) [5].

10 Table 11.2: Set of fitting parameters for the criterion [27].

\section{Figure captions}

Fig. 1: Position of displacement sensors on the front of the target (perforation test).

Fig. 2: Reinforcement in concrete slab.

Fig. 3: Axial behavior, comparison of the shear behavior of concrete for several saturation ratios (curve with circles: $S r=10 \%$; curve with squares: $S r=60 \%$; curve with triangles: $S r=100 \%$ ) [15].

Fig. 4. Mesh of a quarter of projectile and slab [15].

Fig. 5. Numerical results using revised PRM, accounting for free water: projectile and the deformed slab at $30 \mathrm{~ms}$ (a), experimental and numerical evolutions of the projectile velocity (b).

Fig. 6: Model with the revised PRM model: Front face (a), cross section (b), rear face (c).

Fig. 7: Model with the original PRM: Front face (a), cross section (b), rear face (c).

Fig. 8. Experimental observed failure of punching test (IRIS Benchmark [6]): font face (a), rear face (b). Fig. 9: Experimental, numerical and analytical residual velocities.

Fig. 11.1: Hydrostatic behavior, oedometric behavior and consolidated behavior of concrete: mean stress in function of volumetric strain.

Fig. 11.2: Diagram of stress calculation according mixing theory poromechanical when concrete is consolidated.

\section{Appendices}

\subsection{Analytical deviatoric stress in a concrete}

Malecot et al. [27] proposed the following formula to represent the evolution of the maximum

$q_{\max }\left(S_{r}\right)=q_{0}-\frac{S_{r}}{2}\left(3-\mathrm{S}_{r}\right)\left(q_{0}-q_{\text {sat }}\right) \ldots(\mathbf{1 1 . 5})$

35 with

and

$q_{s a t} \approx q_{1}\left(\frac{\sigma_{c_{p 0}}-\lambda \phi_{a i r}^{1 / 3}-\kappa \phi_{c a p}^{1 / 3}-f_{c k} / 3}{q_{1}}+\left(\frac{f_{c k}}{q_{1}}\right)^{1 / \alpha}\right)^{\alpha}$ 
with fitting parameters listed in Table 11.2

Table 11.2

$4 \quad$ Set of fitting parameters for the criterion [27].

\begin{tabular}{lll}
\hline Variable & Symbol & Value \\
\hline Critical shear stress of dry concrete & $q_{I}$ & $980 \mathrm{MPa}$ \\
Slope of the criterion on a logarithmic & $\alpha$ & 0.81 \\
Ultimate consolidation stress & $\sigma_{c_{p 0}}$ & $1280 \mathrm{MPa}$ \\
Entrained air coefficient & $\lambda$ & $210 \mathrm{MPa}$ \\
Capillary porosity coefficient & $\kappa$ & 2350 \\
\hline
\end{tabular}

Table 11.3

Compositions and mechanical properties

\begin{tabular}{|c|c|c|c|c|c|}
\hline Concrete mix (for $1 \mathbf{~ m}^{3}$ ) & LPC & $\begin{array}{l}\mathrm{OC}= \\
\mathrm{EC} 06\end{array}$ & HPC & EC04 & EC08 \\
\hline Gravel $(0.5 / 8 \mathrm{~mm})(\mathrm{kg})$ & 1008 & 1008 & 1008 & 1000 & 991 \\
\hline Sand $(1.8 \mathrm{~mm})(\mathrm{kg})$ & 838 & 838 & 795.4 & 832 & 824 \\
\hline Water $(\mathrm{kg})$ & 169 & 169 & 140 & 136 & 181 \\
\hline Cement CEM II B $42.5(\mathrm{~kg})$ & 263 & 263 & 420 & & \\
\hline Cement CEM I 52.5 N PM ES CP2 (kg) & & & & 349 & 226 \\
\hline Silica fume $\left(\mathrm{kg} / \mathrm{m}^{3}\right)$ & - & - & 46.7 & - & - \\
\hline Entrained air agent $\left(\mathrm{kg} / \mathrm{m}^{3}\right)$ & 0.13 & - & - & & \\
\hline Superplasticizer $(\mathrm{kg})$ & - & - & 4.7 & 4.5 & \\
\hline Density $\left(\mathrm{kg} / \mathrm{m}^{3}\right)$ & 2278 & 2277 & 2415 & 2322 & 2252 \\
\hline Slump (mm) & 120 & 70 & $>200$ & 70 & 140 \\
\hline Uniaxial compressive strength at 28 days $f_{c k}(\mathrm{MPa})$ & 24 & 28.6 & 80 & 57 & 21 \\
\hline Accessible porosity to water $(\%)$ & 10.8 & 11.8 & 8.8 & 7 & 14 \\
\hline Porosity measured by mercury intrusion (at $400 \mathrm{MPa}$ ) & 15.6 & 12.6 & 8.7 & & \\
\hline Entrapped air (measured on fresh concrete) & 8.5 & 3.4 & 4.5 & & \\
\hline Water/cement ratio & 0.6 & 0.64 & 0.3 & 0.39 & 0.80 \\
\hline
\end{tabular}

6 These formulae and parameters have been checked for five types of concretes considered 7 herein (OC, HPC, LPC from [27], and EC04, EC08 from a previous study [44]). These

8 concretes have very different unconfined compressive strengths and porosities, yet their

9 granular stackings closely resemble one another.

10 All concrete mixes and main properties are listed in the table 11.3.

11.2 Improvement of PRM model (from Vu et al. [15])

\subsubsection{Influence of the deviatoric stress on volumetric behavior}

15 The plasticity model assumes that inelastic volumetric and shear strains are obtained

16 independently. The volumetric strain $\varepsilon_{v}$ is assumed to depend on just the mean stress $\sigma_{m}$,

17 while the strain deviator tensor is obtained by means of a perfectly plastic damage model. 
1 The effect of the deviatoric stress $q$ on the volumetric behavior of concrete has therefore not

2 been taken into account in the original PRM coupled model. This original model assumes that

3 the compaction curve, i.e. the volumetric strain $\mathcal{E}_{v}$ vs. mean stress $\sigma_{m}$ curve, is obtained from

4 material data independently of the loading path. [15] show that the inelastic volumetric strain

5 depends on both $q$ and $\sigma_{m}$, which suggests the necessity of including the influence of $q$ in the

6 material compaction curve (whereby $\varepsilon_{v}$ is a function of $\left(\sigma_{m}, q\right)$ ).

7 To improve this PRM model, the curve depicting the volumetric behavior of concrete is not 8 assumed to be bijective; instead, it is assumed bounded by both the hydrostatic and

9 oedometric curves (Fig. 11.1). According to test results, it is indeed assumed that maximum compaction is obtained under an oedometric loading path. Under uniaxial strain conditions,

11 concrete compaction is maximized because dilatancy is being prevented, whereas the 12 hydrostatic loading path yields a lower compaction. The compaction curve oedometric test 13 and the hydrostatic curve are then used as input data due to their ease of access by experimental measurement.

The variation in mean stress $\sigma_{m}$ between the bounded curves is then given by:

20 with:

$$
\alpha=\alpha_{H}+\left(\alpha_{o}-\alpha_{H}\right) \operatorname{Min}\left[\left(\frac{\left(\frac{d q}{d \sigma_{m}}\right)}{\left(\frac{d q}{d \sigma_{m}}\right)_{o}}\right) ; 1\right] \ldots
$$

where (see Fig. 11.1): 
$\left(d q / d \sigma_{m}\right)_{O}=$ oedometric load path direction obtained from an oedometric test.

2

3 In formulae (11.10) and (11.11), the volumetric strain $\varepsilon_{v}$ depends on both the mean stress $\sigma_{m}$

4 and deviatoric shear stress $q$. A hydrostatic loading path contains no shear stress and its

5 behavior follows the hydrostatic curve; however, for a current triaxial loading path with shear

6 stress, the level of compaction is increased.

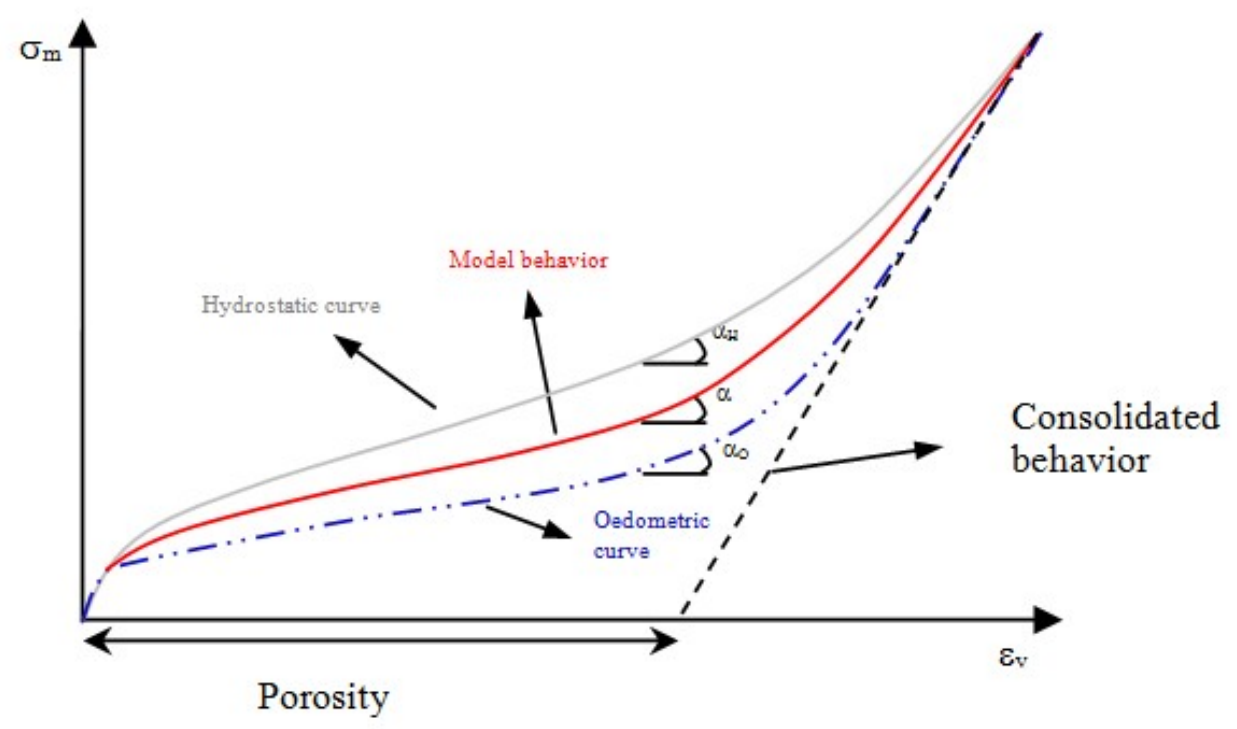

Fig. 11.1 Hydrostatic and oedometric constitutive behaviors and resulting triaxial behavior of concrete: mean stress vs. volumetric strain.

10 Two types of approaches are available to characterize the behavior of a porous medium at its

11 homogenized scale from microscopic-level properties. The "mixing law" approach takes into

12 account, at the microscopic level, the interaction between the two phases (liquid + solid) by

13 means of simple rheological models for each phase, whether associated in series or in parallel.

14 Secondly, the poro-mechanical approach assumes that the mechanics concepts in a continuum

15 mechanics are still valid at the macroscopic scale when the phases (liquid + solid) overlap. 
1 In the original PRM coupled model, the concept of effective stress is applied to take into

2 account the presence of water in confined concrete when using the first approach. The

3 drawback with such an approach is that the material behavior becomes elastic after reaching

4 the consolidation point (once all open pores are closed), which is not observed

5 experimentally. In the revised model, the poro-mechanical approach allows taking the effect

6 of free water into account.

7 The studied porous medium is assumed to be composed of both a solid phase (skeleton) and a

8 fluid phase occupying the voids [37]. The concept of effective stress is introduced to separate

9 fluid pressure in the total pressure calculation $\sigma_{t o t}$, depending on the pore pressure $p$, based on

10 the Mie-Grüneisen equation of state, i.e.:

$$
p=\frac{\rho_{0} C_{0}^{2}\left(\varepsilon_{V}-\varepsilon_{V p s}\right)}{\left(1-s\left(\varepsilon_{V}-\varepsilon_{V p s}\right)\right)^{2}}\left[1-\frac{\Gamma_{0}\left(\varepsilon_{V}-\varepsilon_{V p s}\right)}{2}\right]+\Gamma_{0} \rho_{0} E_{M}
$$

where $C_{0}$ is the speed of sound in water $\left(C_{0}=1,500 \mathrm{~m} / \mathrm{s}\right), \varphi_{0}$ the density $\left(\varphi_{0}=1,000 \mathrm{~kg} / \mathrm{m}^{3}\right.$ for water), $s$ and $\Gamma_{0}$ two Mie-Grüneisen coefficients ( $s=1.75$ and $\Gamma_{0}=0.28$ for water), and $E_{M}$ the internal energy per unit mass, with this energy being considered negligible for water temperature and ambient pressure.

The total pressure $\sigma_{\text {tot }}$ also depends on the stress $\sigma_{M}$ transmitted by the matrix at a macroscopic scale, and $b$ the Biot coefficient which depends on the nature of the porosity. $\sigma_{M}$ and $b$ can be obtained by applying the following formulae:

$\sigma_{M}=K_{0} \mathcal{E}_{v}$

$b=1-\frac{K_{0}}{K_{S}}$

where $K_{0}$ is the modulus of the drained material, $\varepsilon_{V}$ the volumetric strain at the homogenized scale, and $\mathrm{K}_{\mathrm{S}}$ the compressibility modulus of the skeleton.

From Equation (11.4), in the particular case where $K_{0}<<K_{s}, b$ is then close to 1 , a result that simplifies Equation (2.2) and becomes $\sigma_{t o t}=\sigma_{M}+p$ (i.e. Terzaghi's formula). In contrast, 
1 when $K_{0} \approx K_{S}$ (case of dry concrete), b tends to 0 . Thanks to homogenization of the drained

2 porous medium, the ratio $K_{0} / K_{S}$ can be estimated as follows:

$$
\frac{K_{0}}{K_{S}}=(1-\phi)^{3}
$$

4 where $\phi$ is the porosity of the porous medium at the current state.

5

6 With this new hypothesis, whenever the material reaches the consolidation point (i.e. void 7 pores become closed), the volumetric behavior remains nonlinear given that the voids filled 8 with water continue to be compressed under compaction. Another advantage of this model 9 improvement is the unique consolidation point instead of two points in the original PRM model (Fig. 11.2).

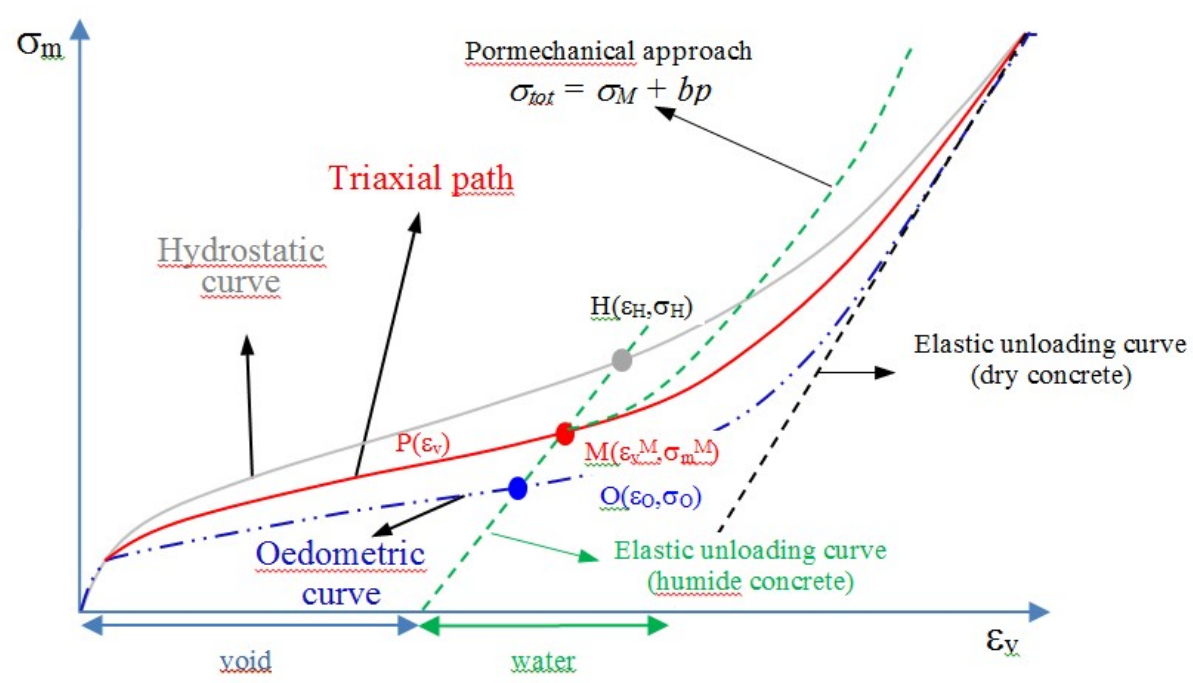

Fig. 11.2 Stress calculation diagram according to the poro-mechanical approach, as the concrete consolidates. 


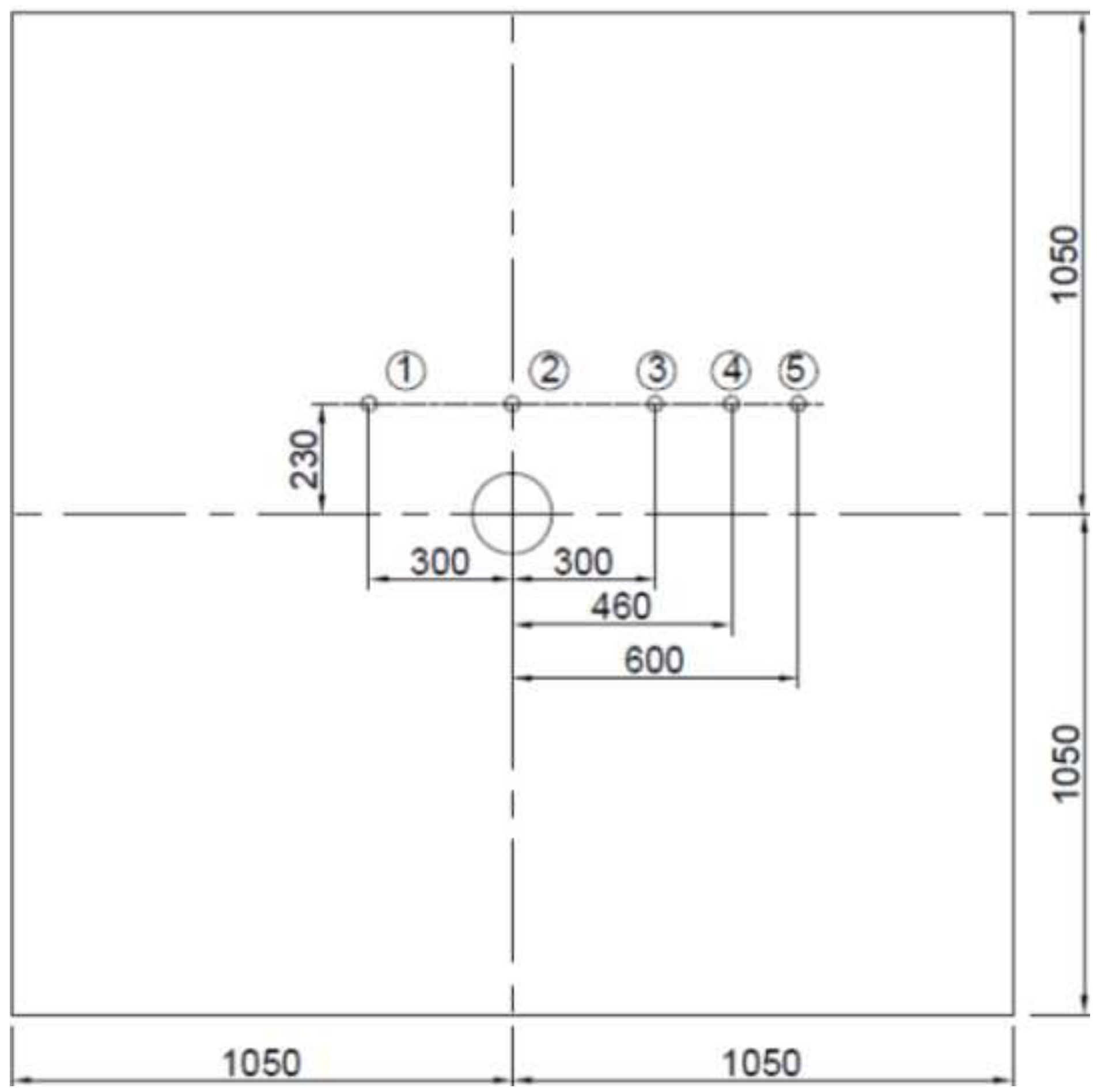




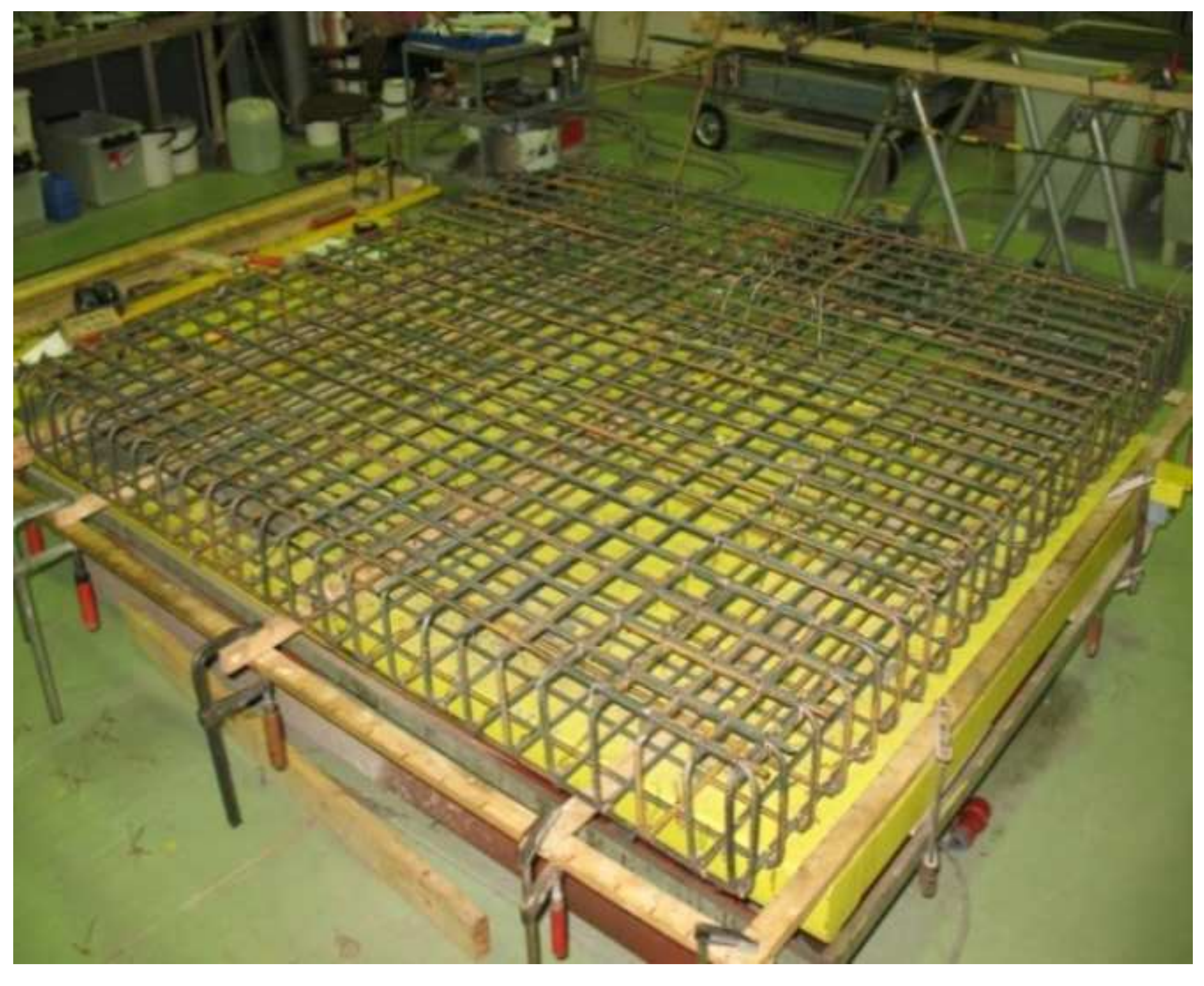




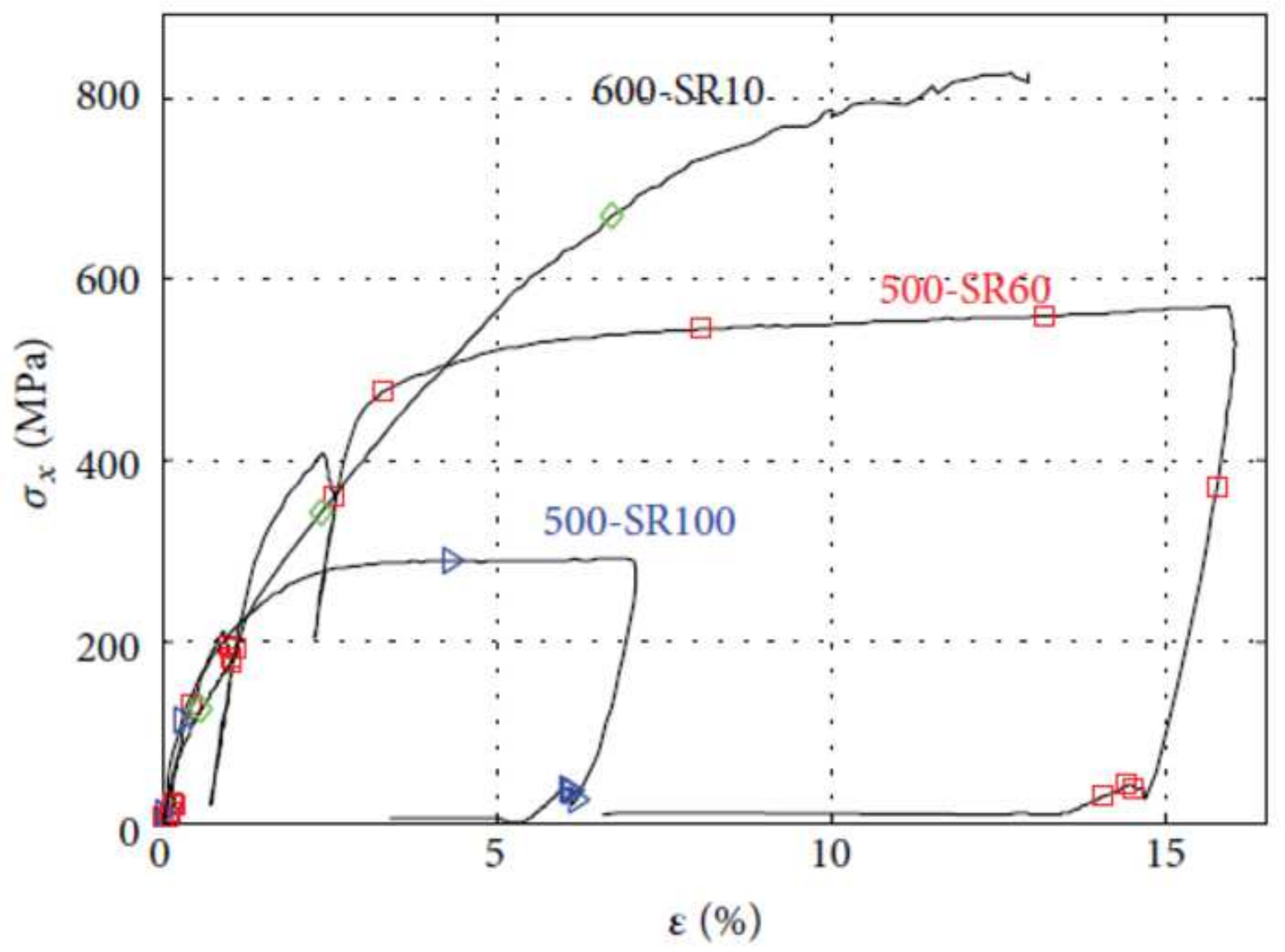




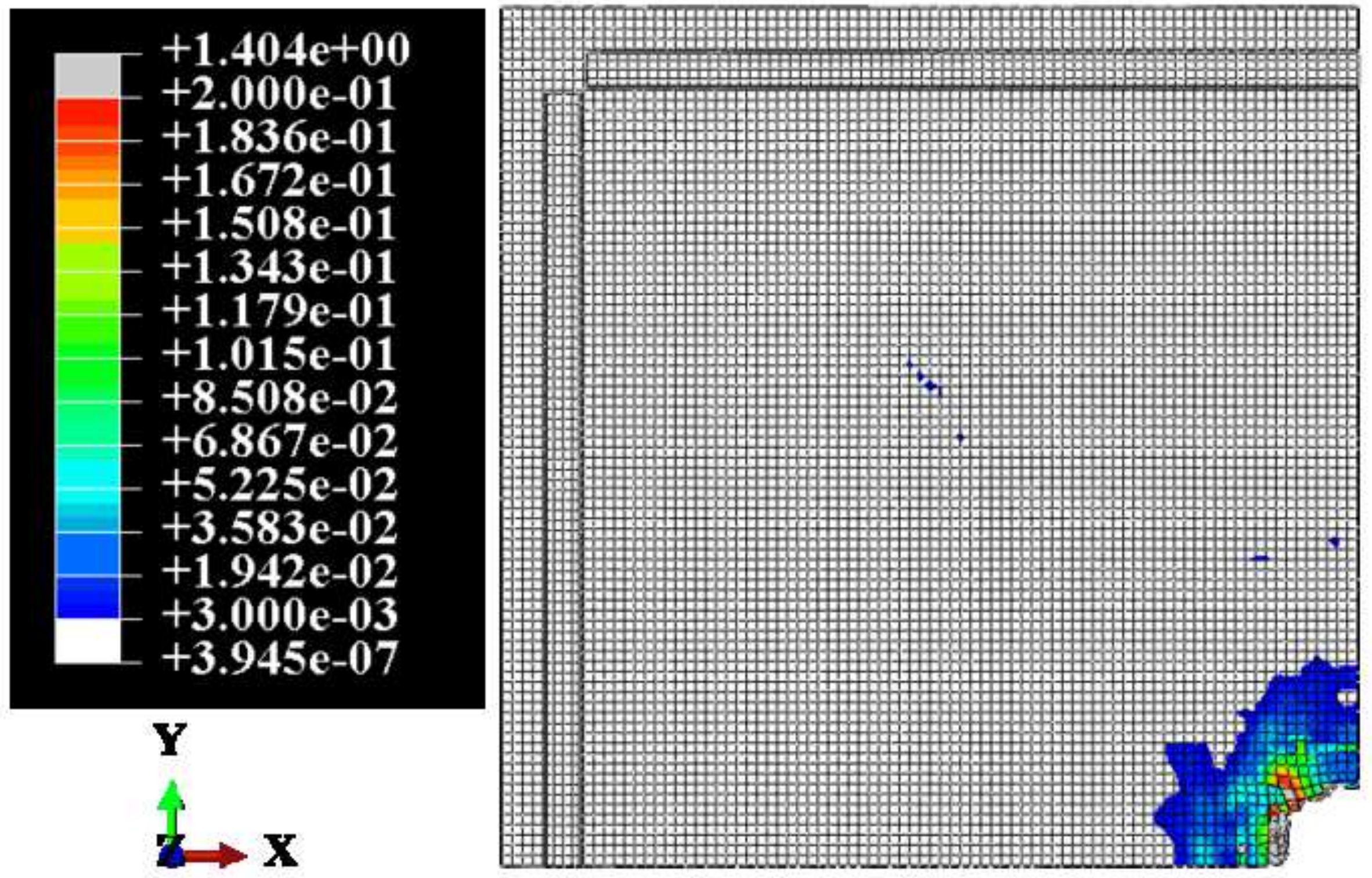



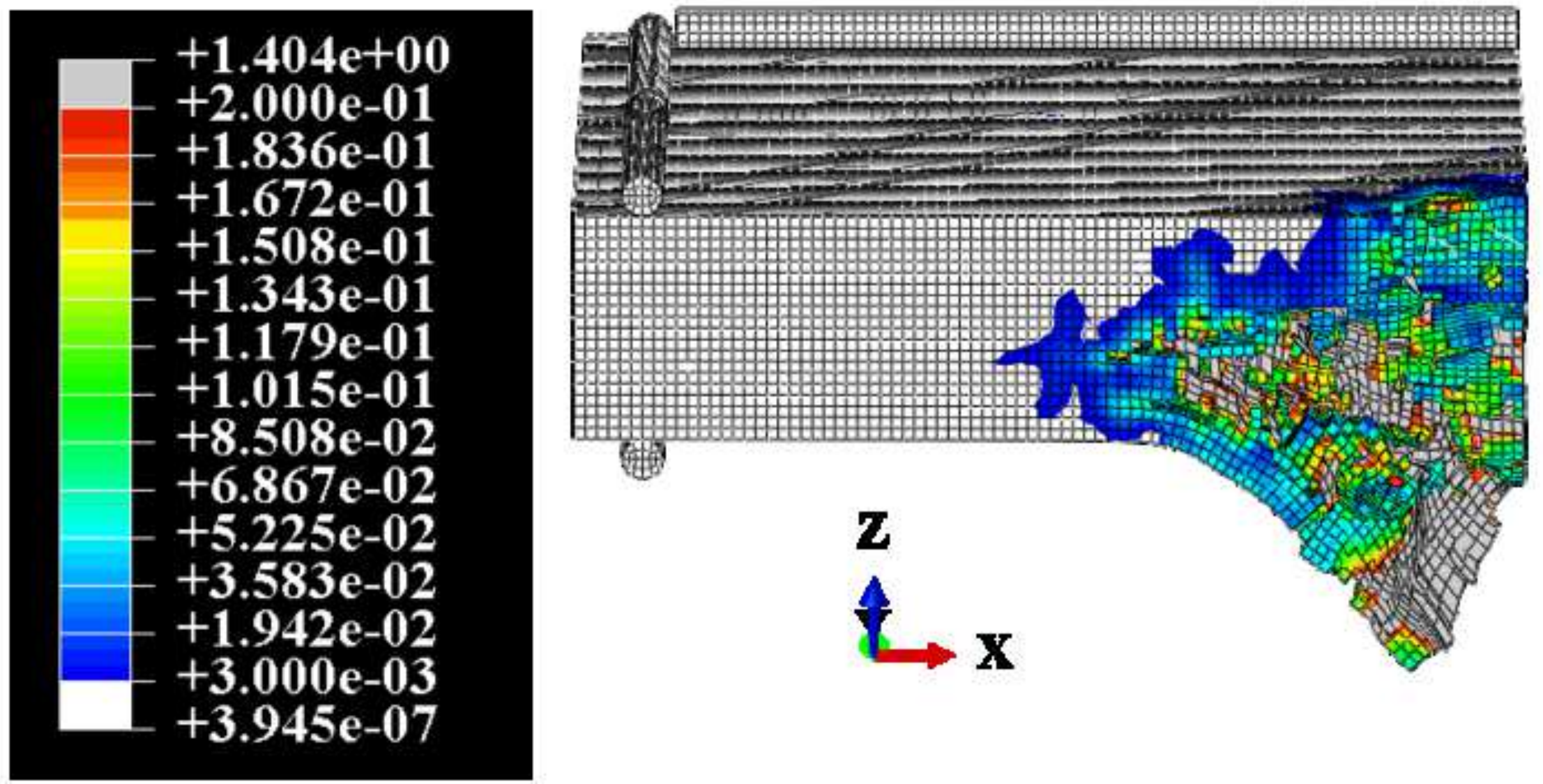

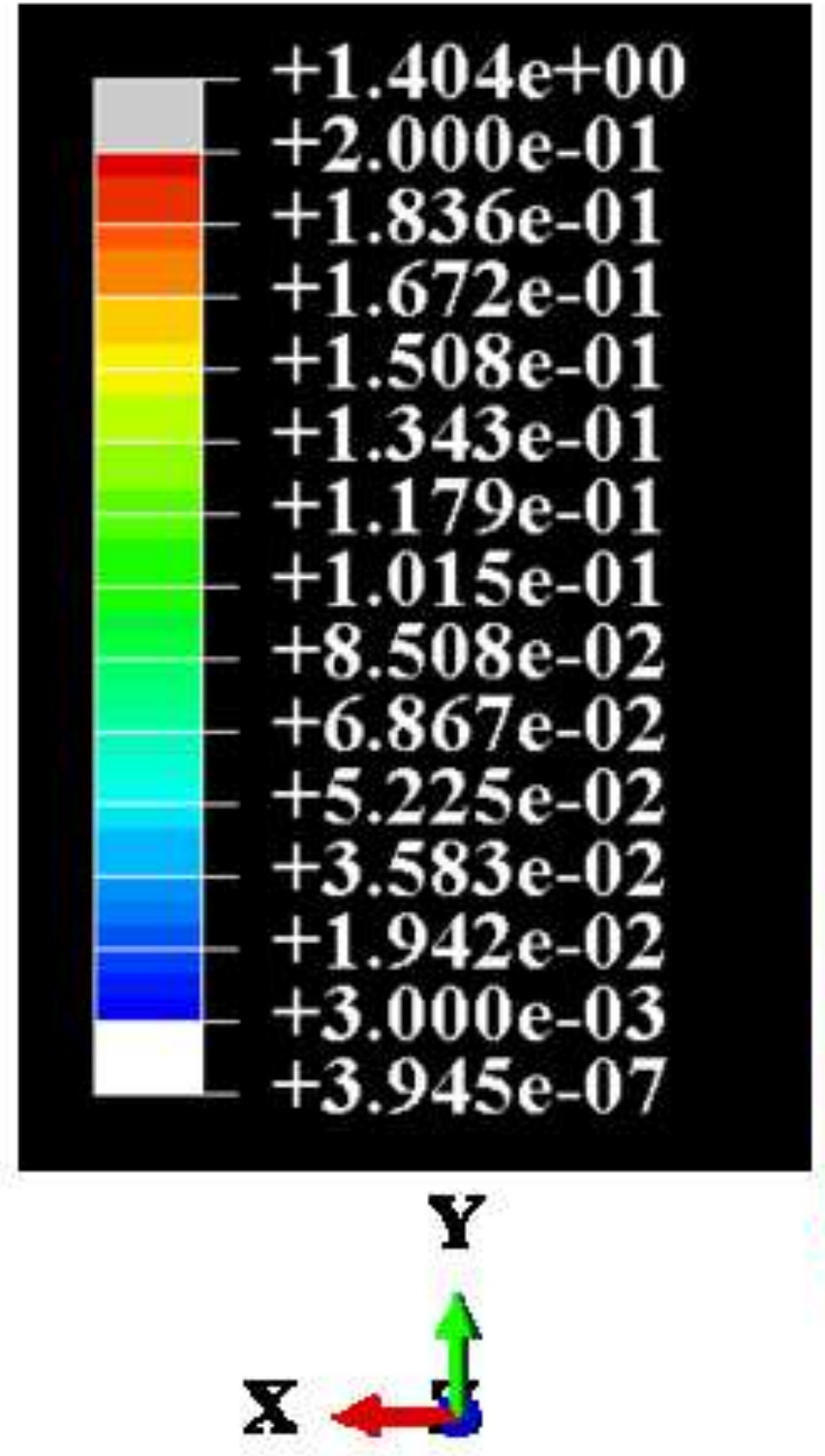

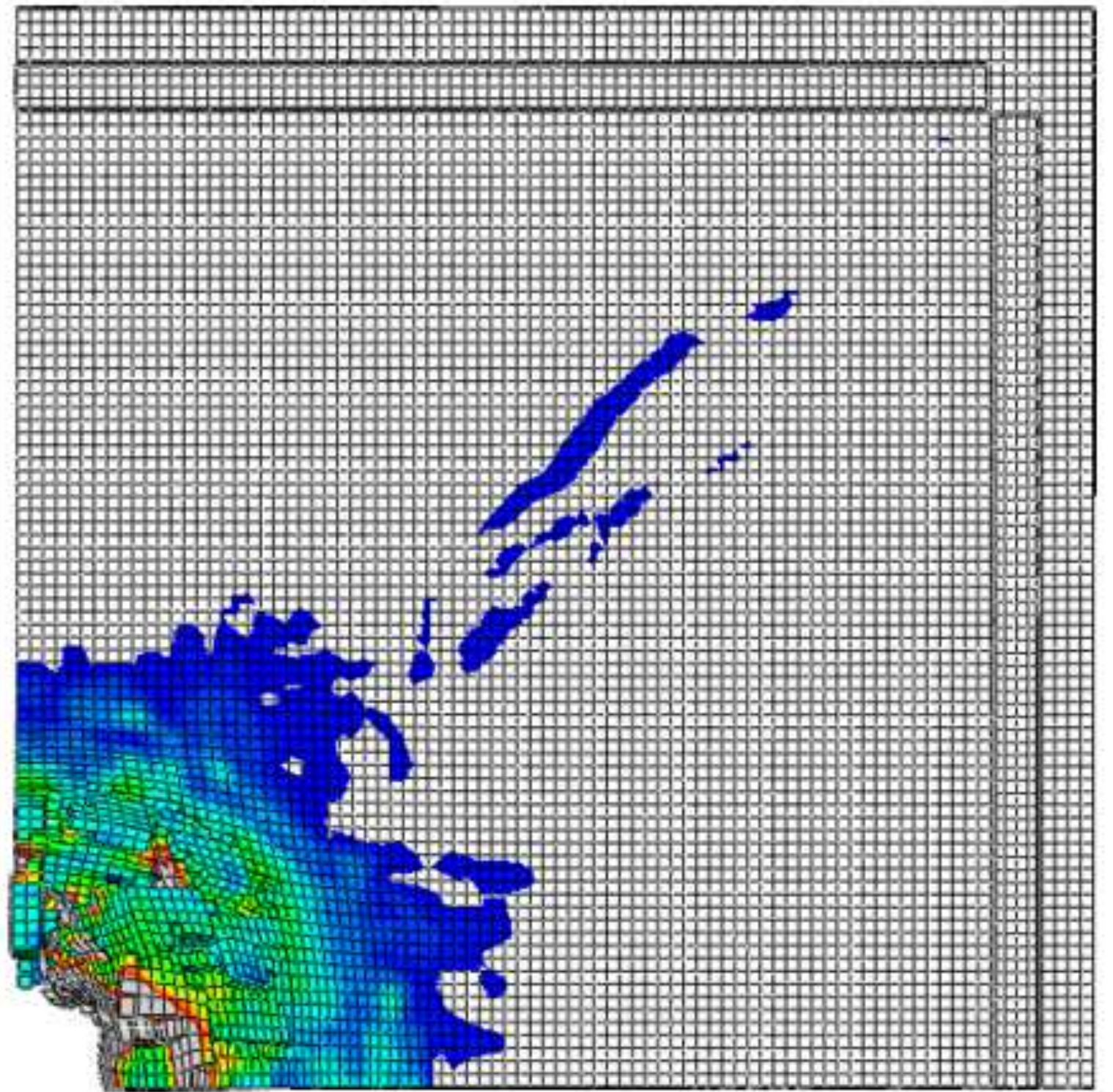



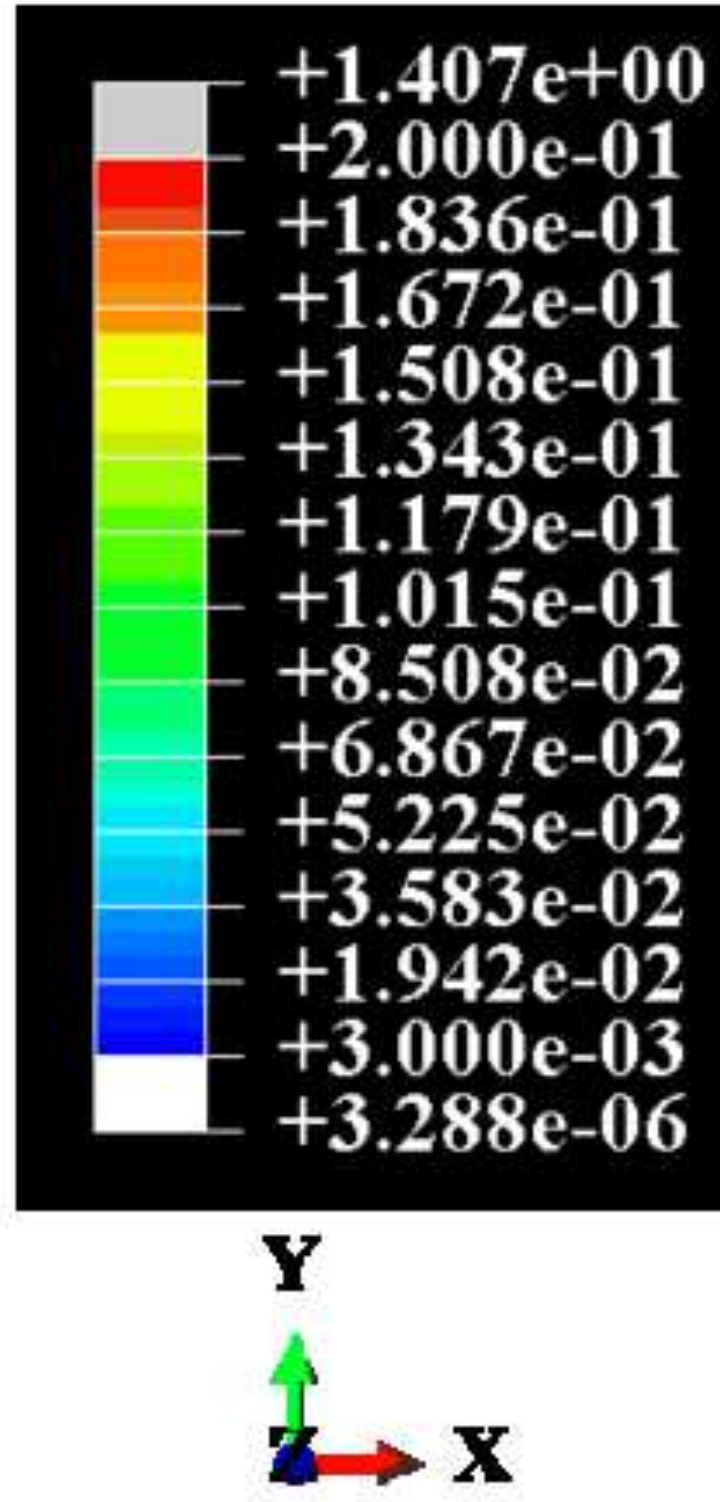

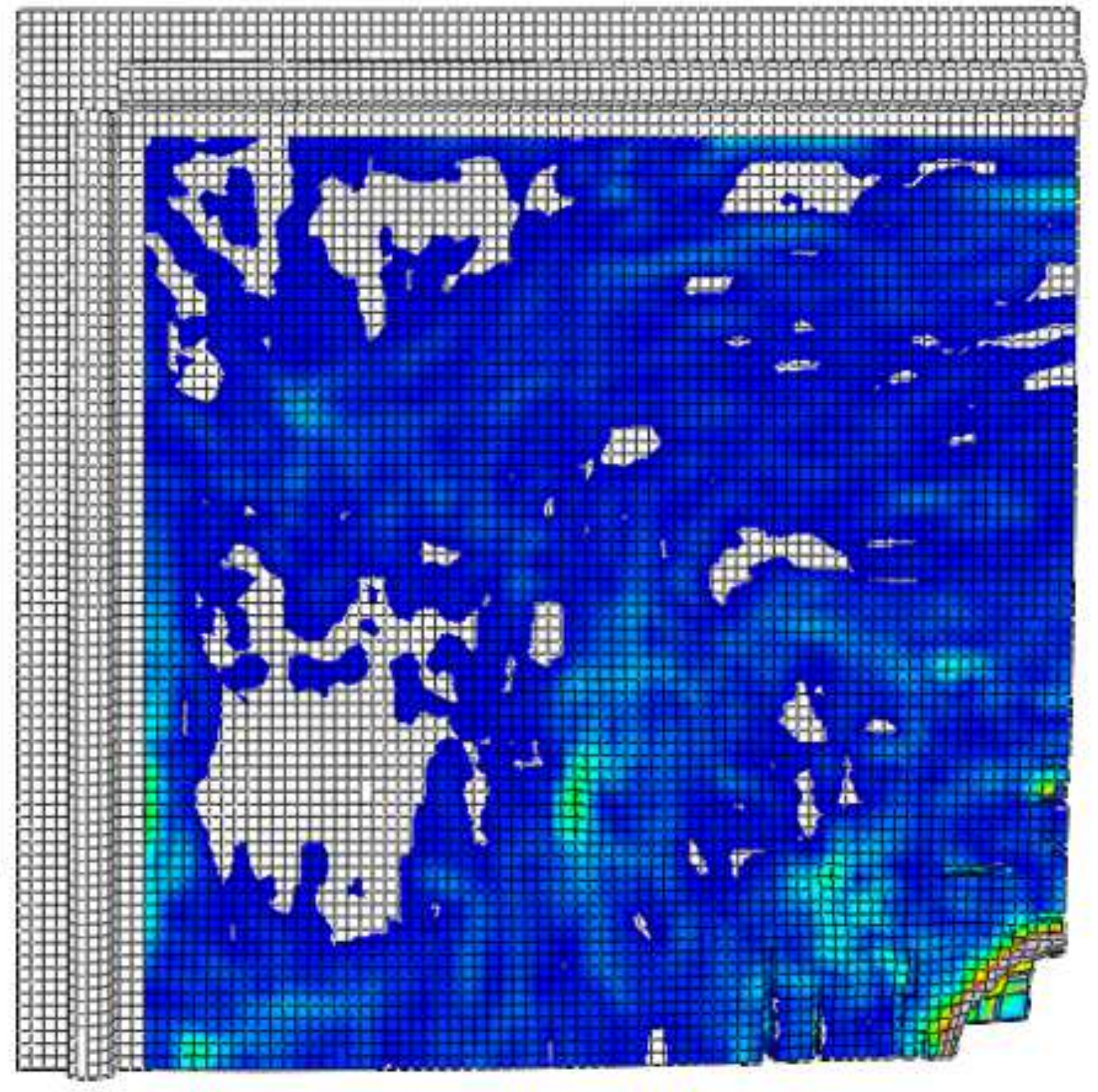



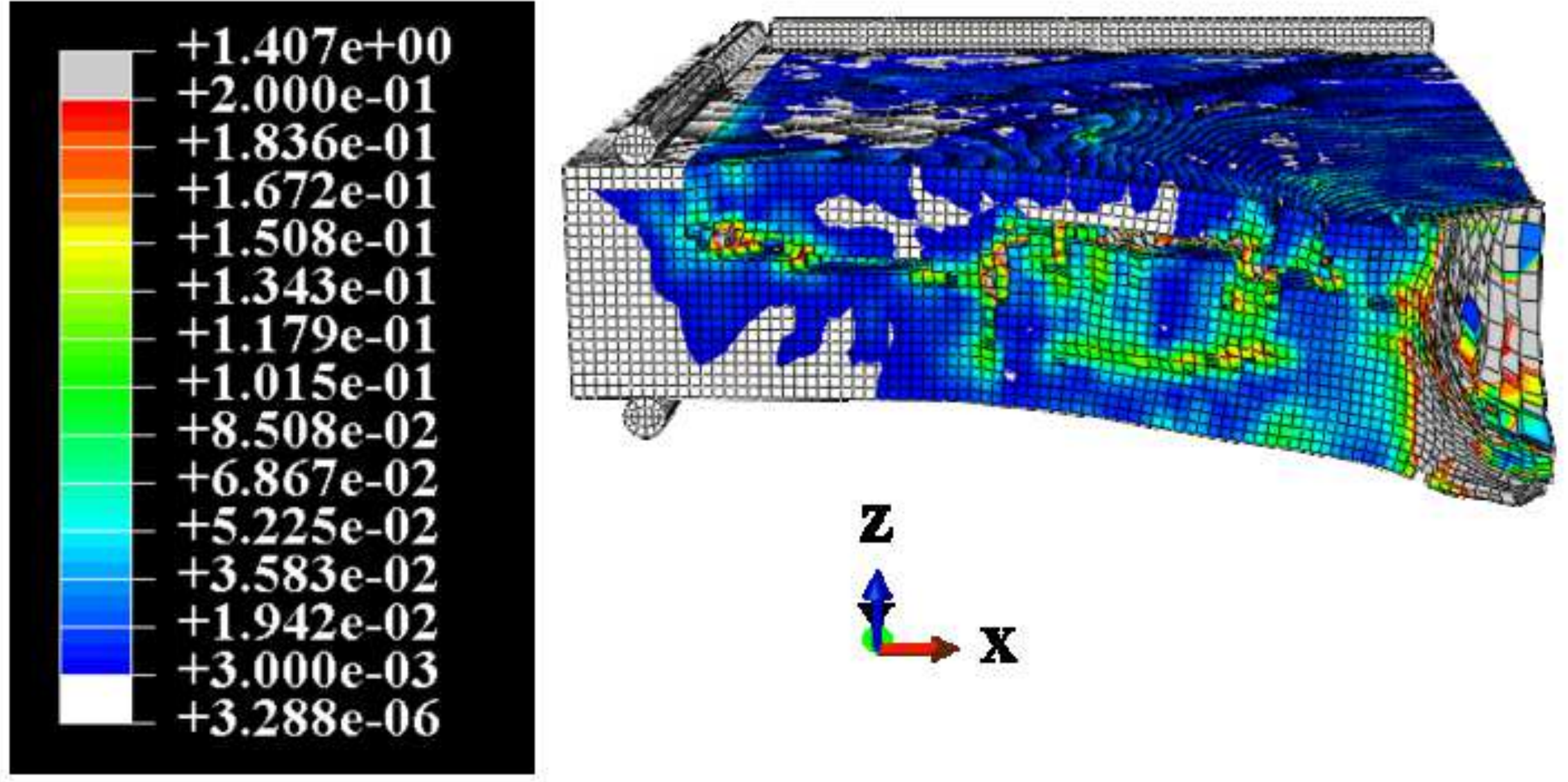

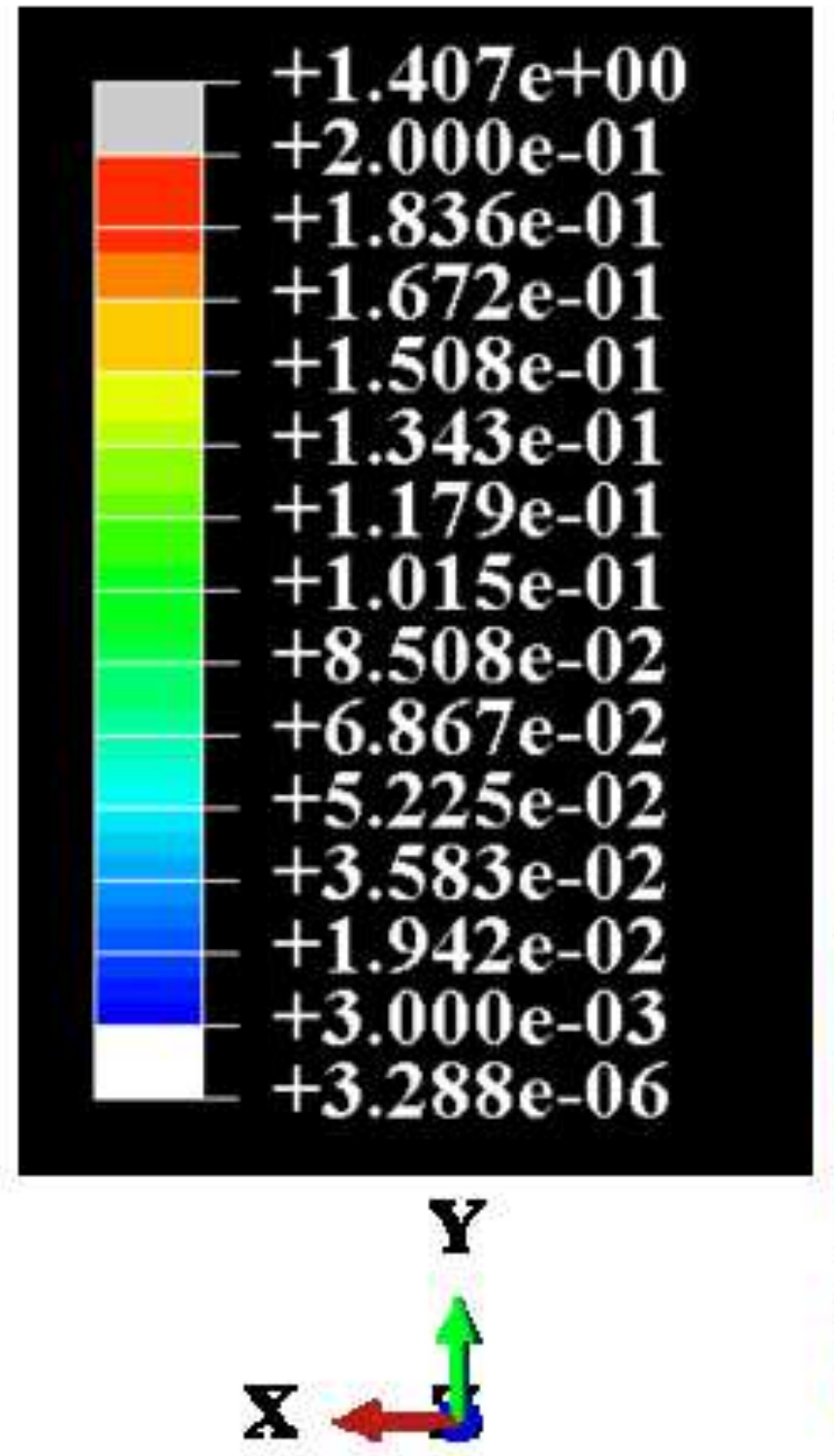

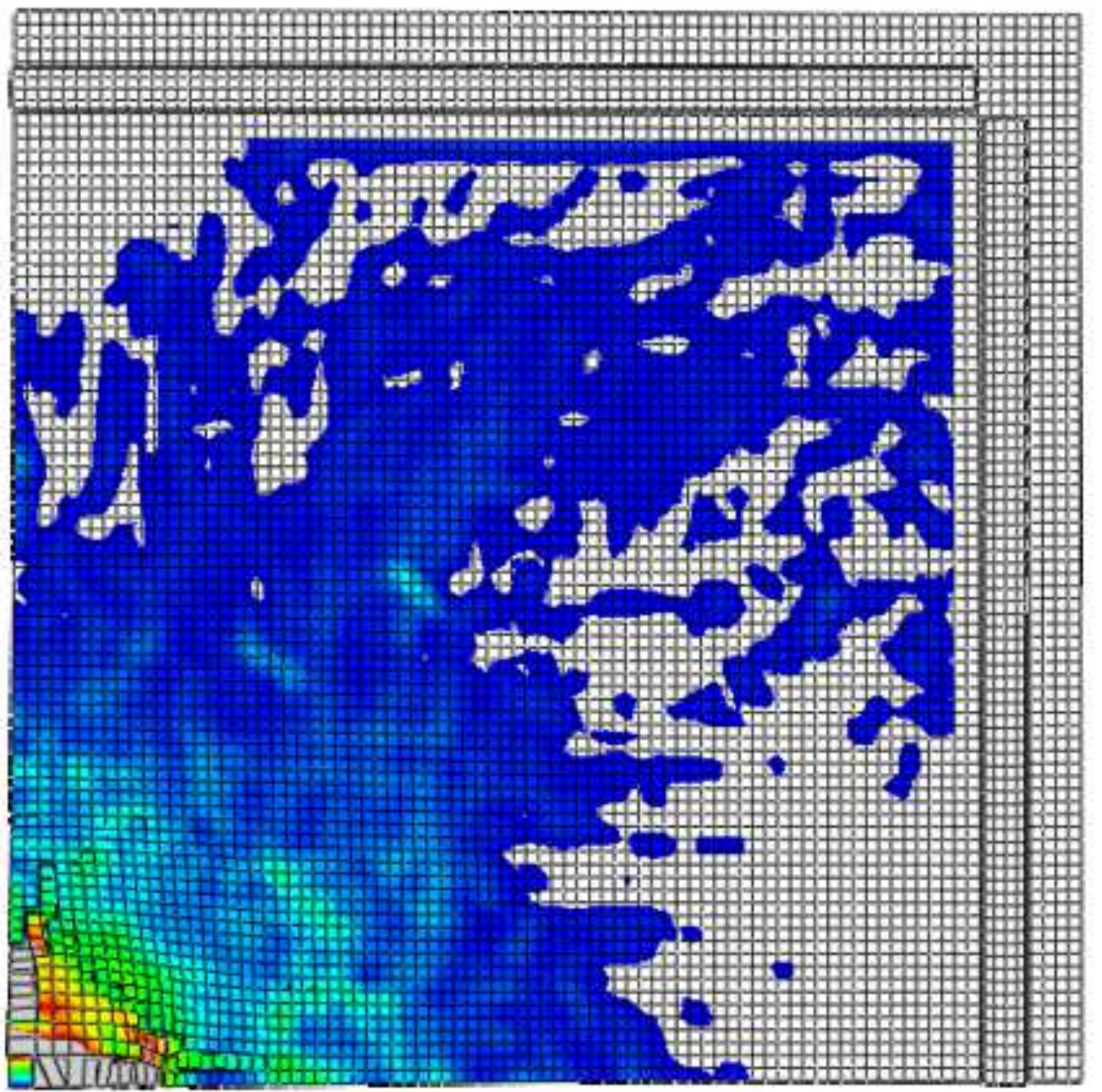




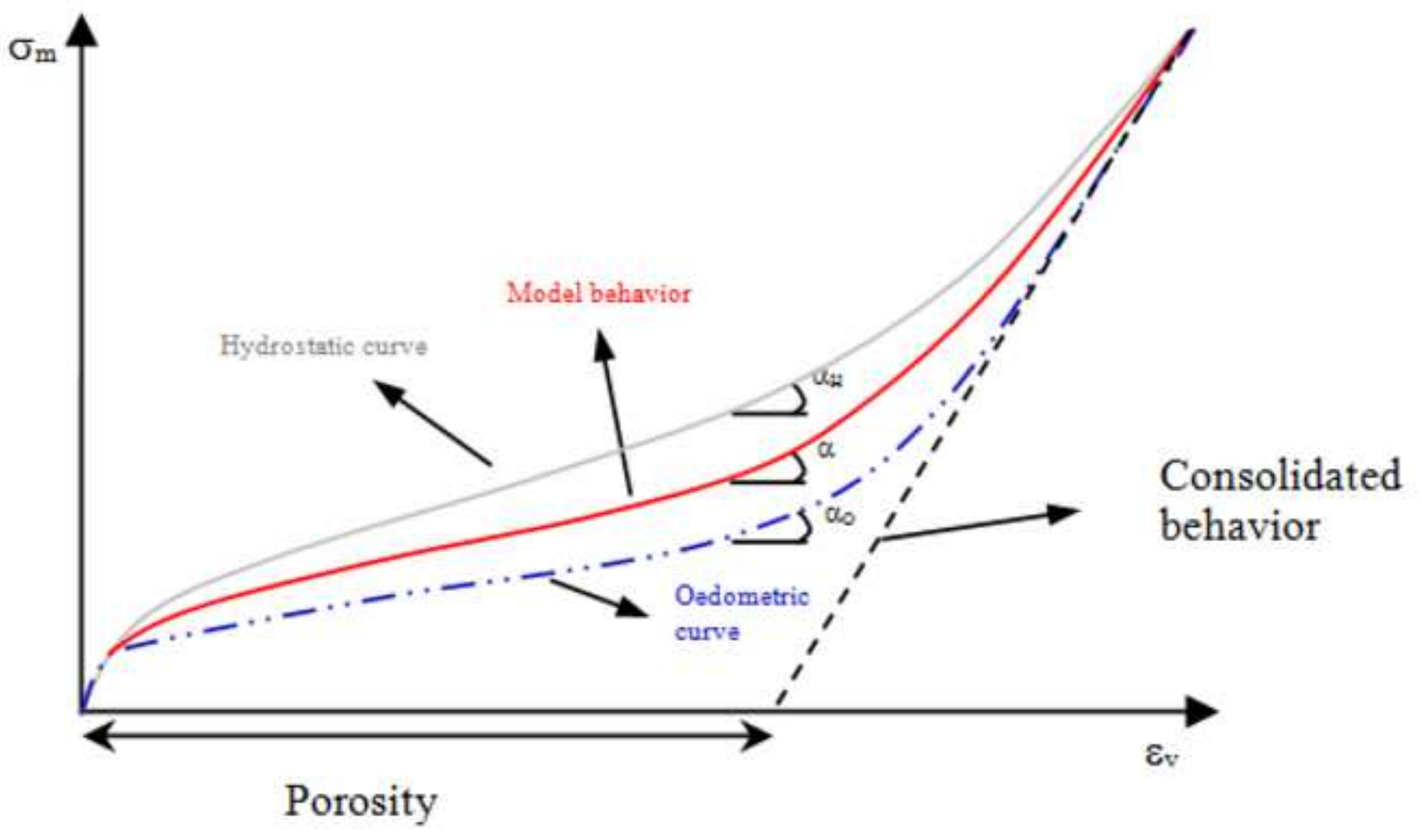




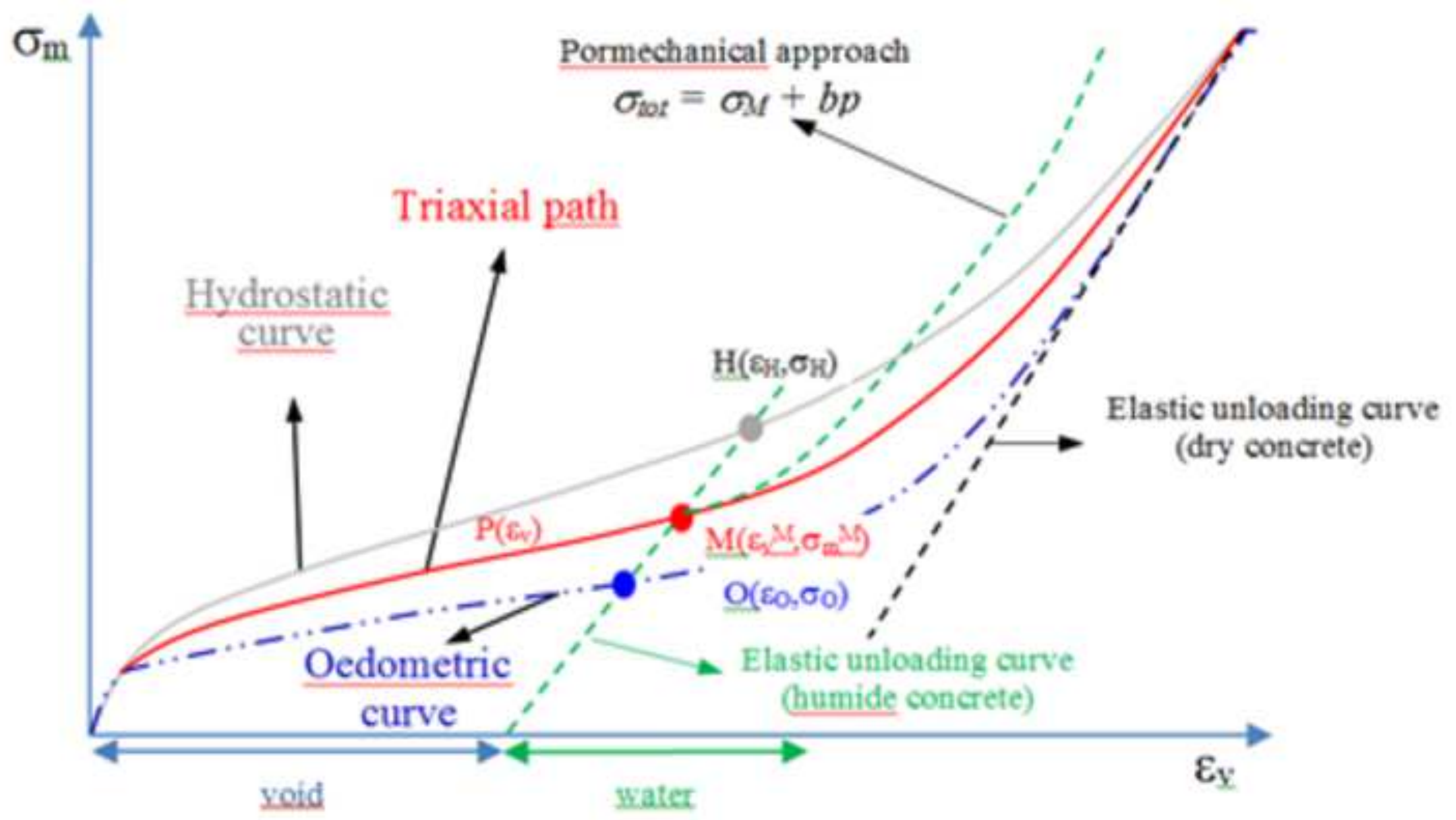


Backside of the

wall after the test

$\sim 121 \mathrm{~kg}$

\section{OECOINEACSNURGE \\ Damages \\ Scabbed area: $1.1227 \mathrm{~m}^{2}$ \\ Concrete loss:}

P3 Punching test

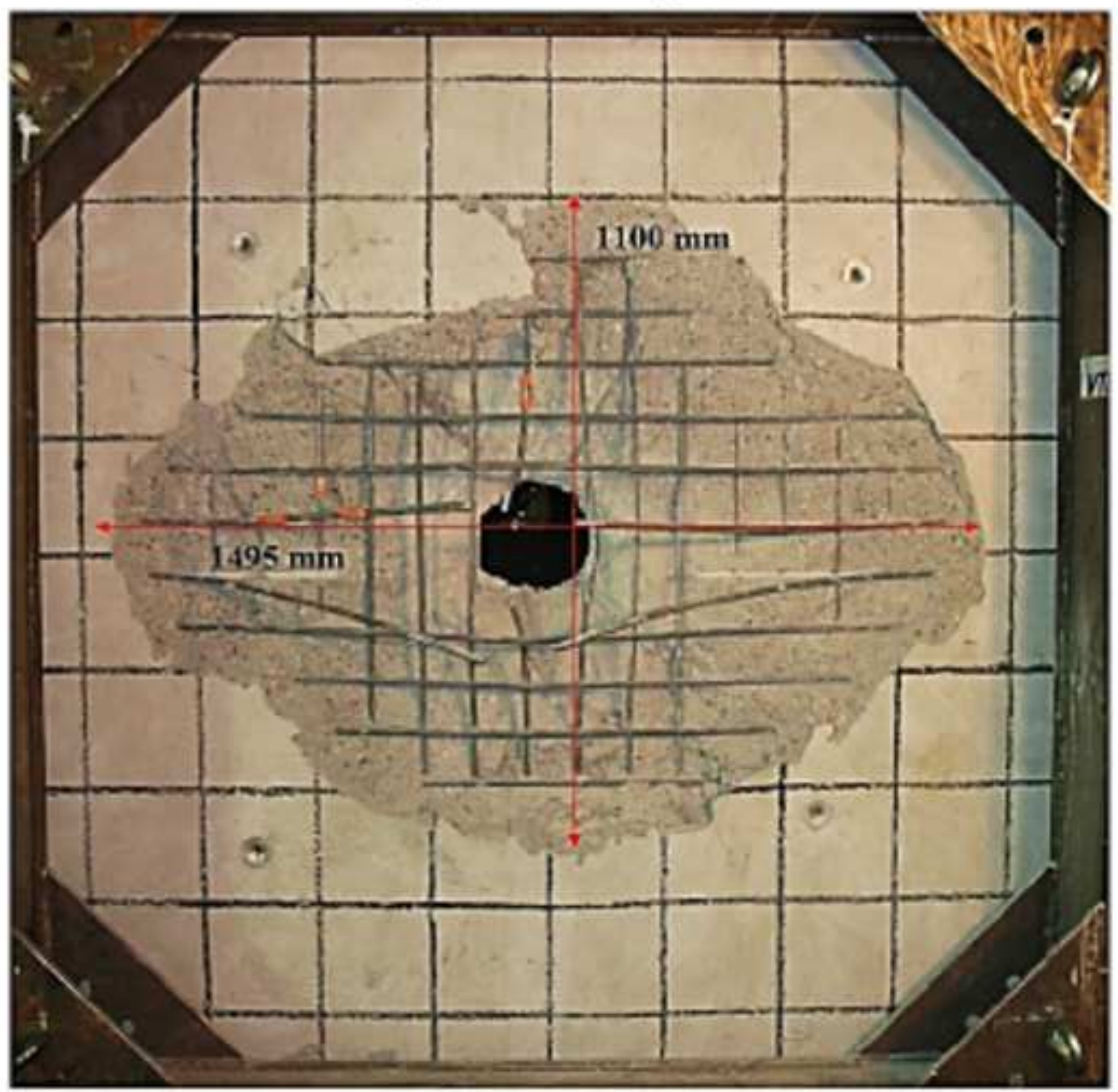

RIS_2010 Benchmark 
OECDNEACSNIIAGE

rs runching test

IRIS_2010 Benchmark

Damages

Frontside of the wall after the test

Impact velocity: $136.46 \mathrm{~m} / \mathrm{s}$

Residual velocity: $35.8 \pm 1.6 \mathrm{~m} / \mathrm{s}$

Spalling area: $0.0952 \mathrm{~m}^{2}$

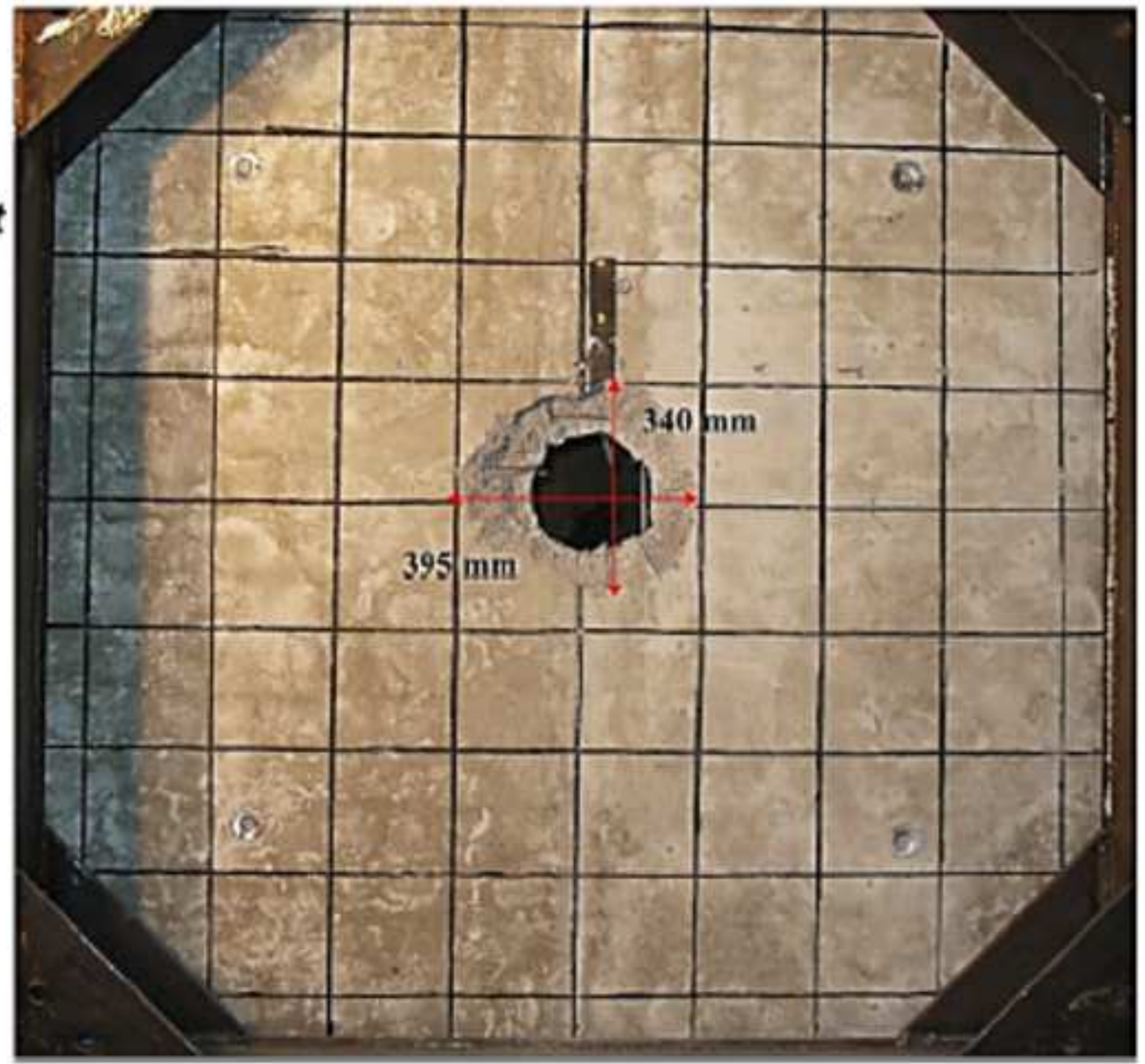



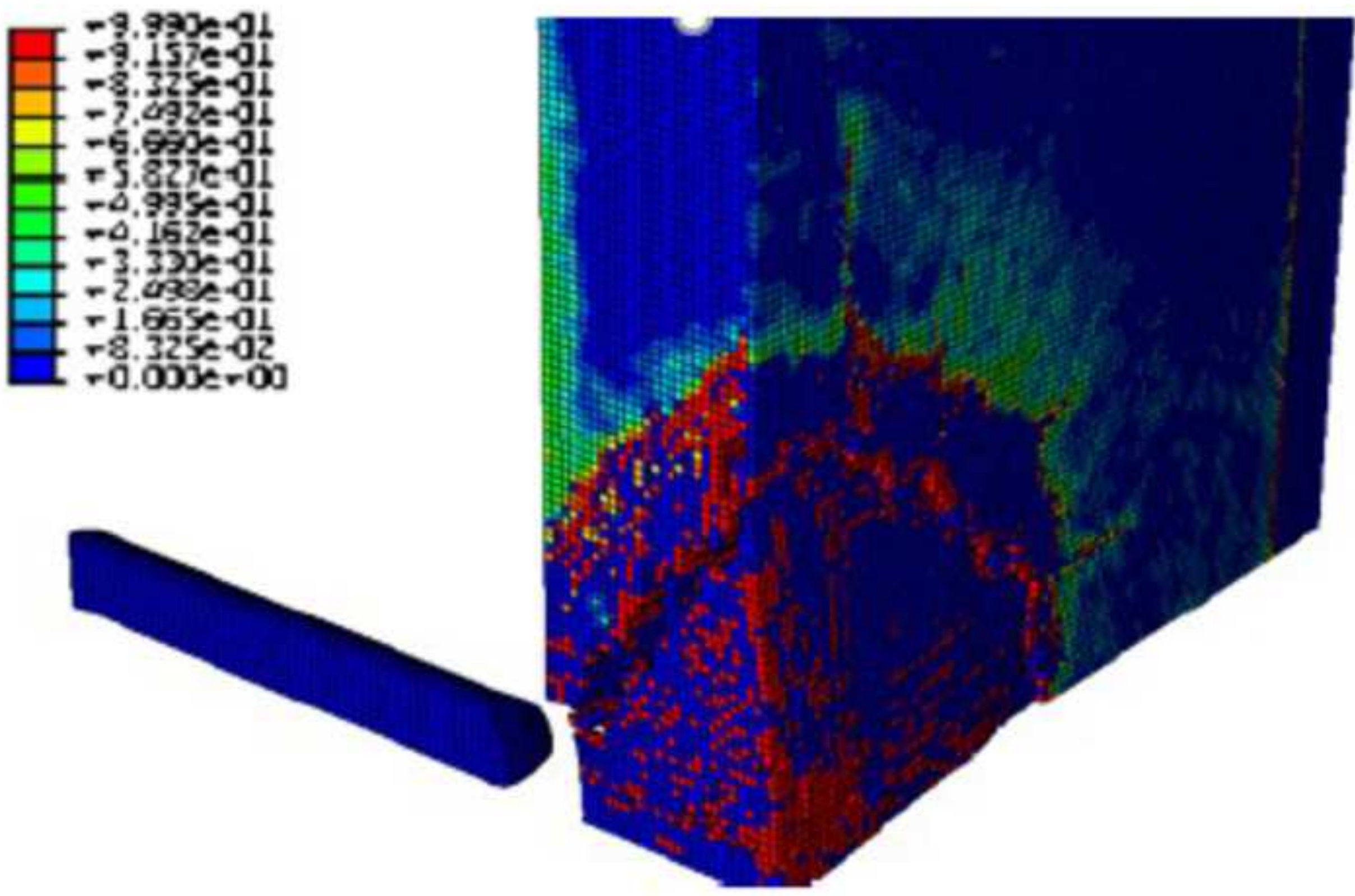


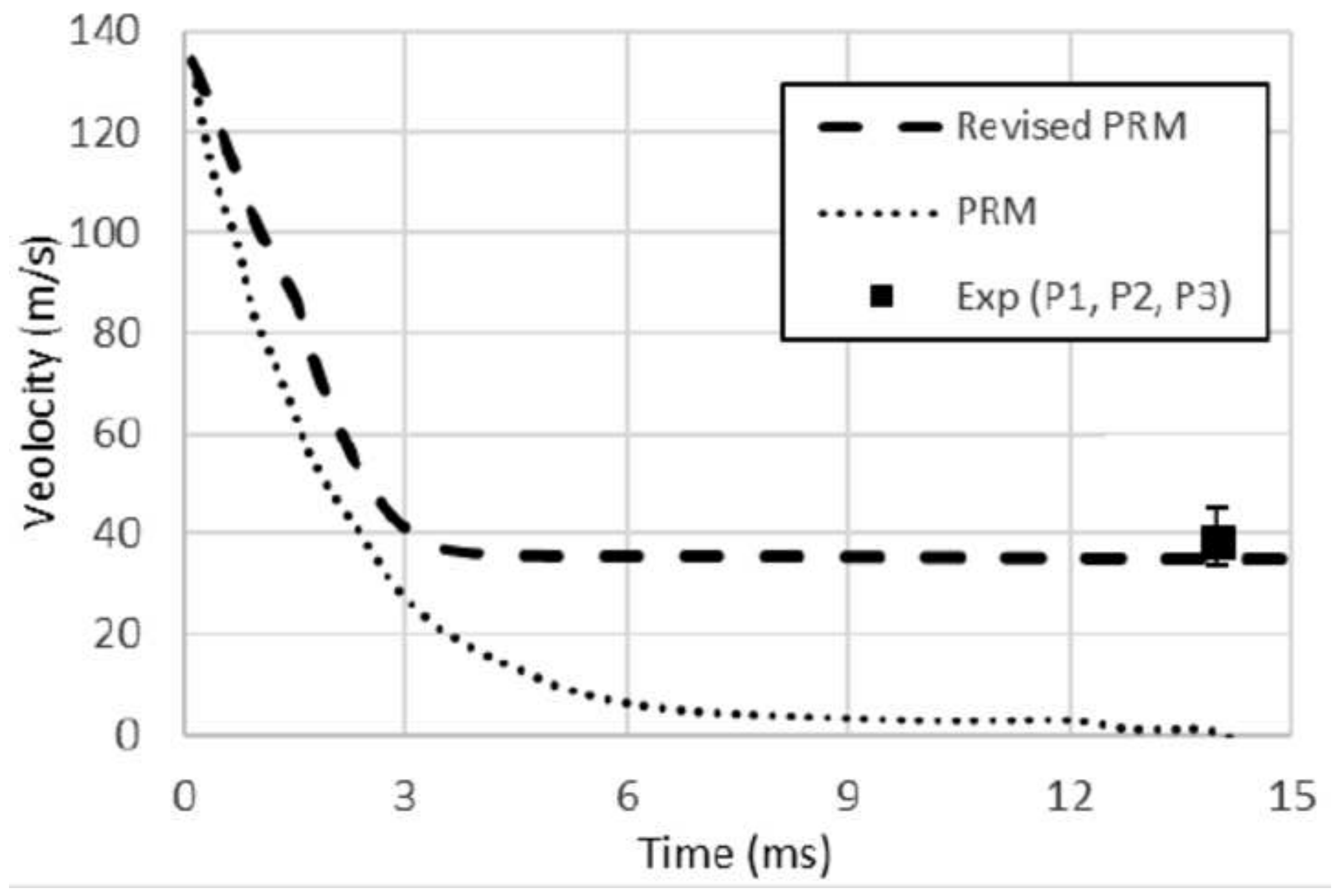




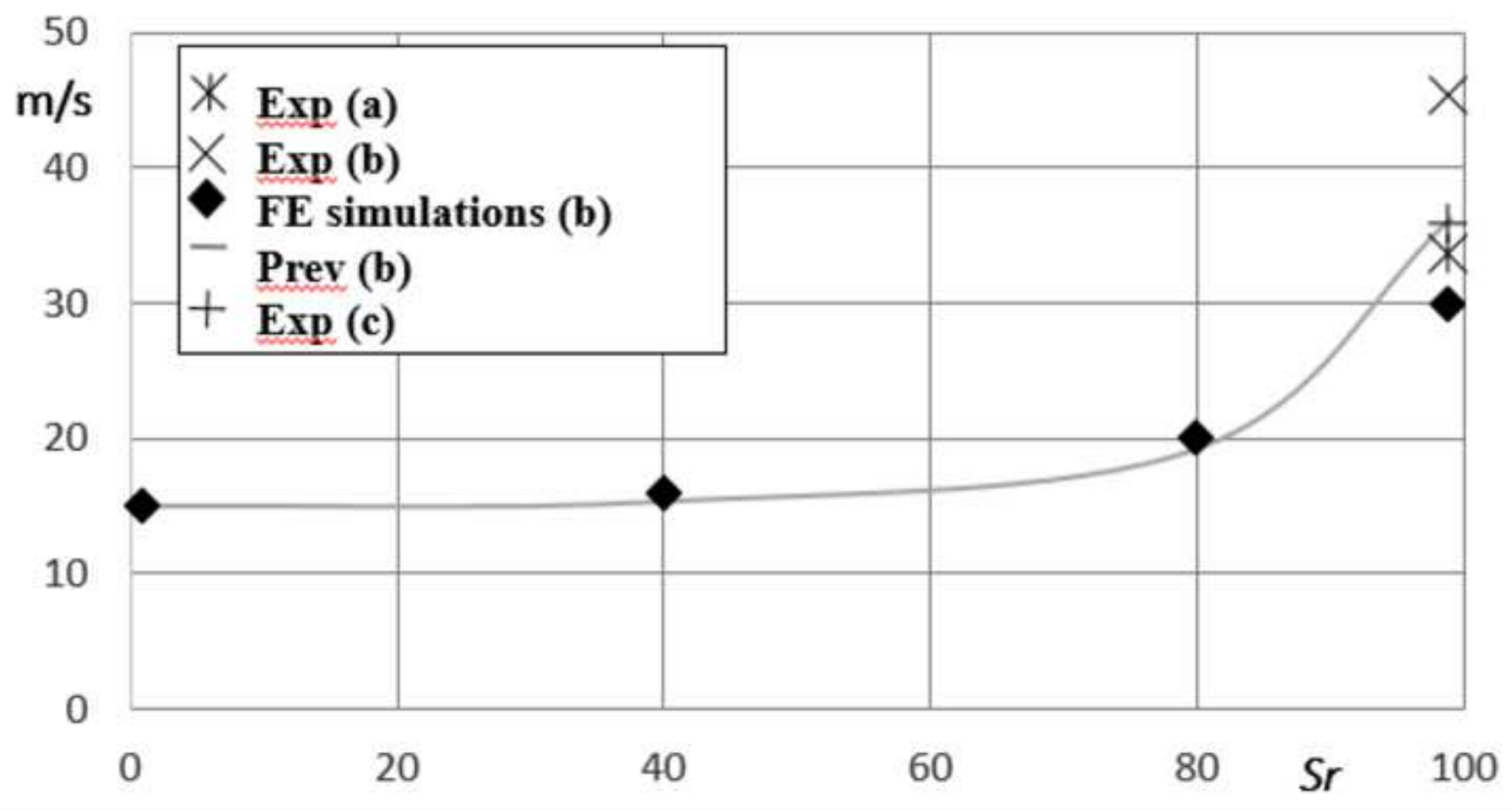

